\title{
State of the Evidence Traffic Lights 2019: Systematic Review of Interventions for Preventing and Treating Children with Cerebral Palsy
}

\author{
Iona Novak ${ }^{1} \cdot$ Catherine Morgan ${ }^{1} \cdot$ Michael Fahey $^{2,3} \cdot$ Megan Finch-Edmondson ${ }^{1} \cdot$ Claire Galea $^{1,4} \cdot$ Ashleigh Hines $^{1} \cdot$ \\ Katherine Langdon ${ }^{5}$ - Maria Mc Namara ${ }^{1}$ - Madison CB Paton ${ }^{1}$ - Himanshu Popat ${ }^{1,4}$. Benjamin Shore ${ }^{6}$. \\ Amanda Khamis ${ }^{1}$ - Emma Stanton ${ }^{1}$. Olivia P Finemore ${ }^{1} \cdot$ Alice Tricks $^{1} \cdot$ Anna te Velde $^{1} \cdot$ Leigha Dark $^{7}$. \\ Natalie Morton ${ }^{8,9} \cdot$ Nadia Badawi $^{1,4}$
}

Published online: 21 February 2020

(C) The Author(s) 2020

\begin{abstract}
Purpose of Review Cerebral palsy is the most common physical disability of childhood, but the rate is falling, and severity is lessening. We conducted a systematic overview of best available evidence (2012-2019), appraising evidence using GRADE and the Evidence Alert Traffic Light System and then aggregated the new findings with our previous 2013 findings. This article summarizes the best available evidence interventions for preventing and managing cerebral palsy in 2019.

Recent Findings Effective prevention strategies include antenatal corticosteroids, magnesium sulfate, caffeine, and neonatal hypothermia. Effective allied health interventions include acceptance and commitment therapy, action observations, bimanual training, casting, constraint-induced movement therapy, environmental enrichment, fitness training, goal-directed training, hippotherapy, home programs, literacy interventions, mobility training, oral sensorimotor, oral sensorimotor plus electrical stimulation, pressure care, stepping stones triple $\mathrm{P}$, strength training, task-specific training, treadmill training, partial body weight support treadmill training, and weight-bearing. Effective medical and surgical interventions include anti-convulsants, bisphosphonates, botulinum toxin, botulinum toxin plus occupational therapy, botulinum toxin plus casting, diazepam, dentistry, hip surveillance, intrathecal baclofen, scoliosis correction, selective dorsal rhizotomy, and umbilical cord blood cell therapy. Summary We have provided guidance about what works and what does not to inform decision-making, and highlighted areas for more research.
\end{abstract}

Keywords Cerebral palsy $\cdot$ Systematic review $\cdot$ Traffic light system $\cdot$ Evidence based $\cdot$ GRADE

This article is part of the Topical Collection on Pediatric Neurology

Electronic supplementary material The online version of this article (https://doi.org/10.1007/s11910-020-1022-z) contains supplementary material, which is available to authorized users.

Iona Novak

inovak@cerebralpalsy.org.au

1 Cerebral Palsy Alliance Research Institute, Discipline of Child \& Adolescent Health, Faculty of Medicine \& Health, The University of Sydney, PO Box 6427, Frenchs Forest, Sydney, NSW 2086, Australia

2 Department of Paediatric Neurology, Monash Health, Clayton, Victoria, Australia

3 Department of Paediatrics, Monash University, Clayton, Victoria, Australia

4 Grace Centre for Newborn Care, Children's Hospital at Westmead, Westmead, New South Wales, Australia
5 Department of Paediatric Rehabilitation, Kids Rehab WA, Perth Children's Hospital, Perth, Australia

6 Department of Orthopedic Surgery, Boston Children's Hospital, Harvard Medical School, Boston, MA, USA

7 Allied and Public Helath, Faculty of Health Sciences, Western Sydney University, Sydney, New South Wales, Australia

8 Allied and Public Helath, Faculty of Health Sciences, Western Sydney University, Sydney, New South Wales, Australia

9 School of Allied Health, Australian Catholic University, North Sydney, New South Wales, Australia 


\section{Introduction}

Cerebral palsy is the most common physical disability of childhood. In the last decade, major discoveries have been made in early diagnosis, prevention, and treatment, altering incidence, prognosis, and treatment responsivity. In highincome countries such as Australia, motor severity has lessened and the incidence of cerebral palsy has fallen by a staggering $30 \%$ [1]. Non-ambulant forms of cerebral palsy, cooccurring epilepsy, and co-occurring intellectual disability are less frequent, meaning more children than ever before can walk [2]. Epidemiologists propose that the reduction in incidence and severity is likely due to a combination of comprehensive obstetric and neonatal intensive care interventions.

In recent years, the cerebral palsy treatment evidence base has continued to expand rapidly, providing clinicians and families with the possibility of newer, safer, and more effective interventions. Since we last provided a comprehensive summary of the cerebral palsy intervention evidence in 2013, another 200+ systematic reviews have been published [3•]. This increasing volume of research evidence makes keeping up-todate challenging for busy clinicians and overwhelming for families. Furthermore, the introduction of new interventions extends what clinicians need to know to allow sound clinical reasoning and decision-making [4].

This paper aimed to systematically describe the best available evidence for cerebral palsy interventions in 2019. We searched for the best available evidence published after 2012 and aggregated the new findings with our previous 2013 summary of evidence, using the updated GRADE system and the Evidence Alert Traffic Light System [5, 6]. The purpose of the paper was to describe what treatments have demonstrated evidence and highlight areas for more research. We rated the whole cerebral palsy intervention evidence base within the one paper to provide families, clinicians, managers, and policy makers with a helicopter view of best available intervention evidence to (a) inform decision-making by succinctly describing effective, emergent, and ineffective care; (b) aid comparative clinical decision-making about alike interventions and indications; and (c) provide a comprehensive resource to aid the creation of knowledge translation tools to promote evidence implementation.

\section{Methods}

\section{Study Design}

We conducted a systematic overview of best available evidence using the systematic review of systematic reviews methodology in order to provide an overview of the current state of the evidence [7].

\section{Search Strategy}

Our review was carried out using a protocol based upon recommendations from the Cochrane Collaboration and reported according to the PRISMA statement $[8,9 \bullet \bullet]$. Relevant articles were identified by searching: CINAHL (2012 to 2019); Cochrane Database of Systematic Reviews [www.cochrane. org]; EMBASE (2012 to 2019); ERIC (2012 to 2019); PubMED (2012 to 2019), PsycINFO (2012 to 2019), MEDLINE (2012 to 2019), OTSeeker [www.otseeker.com]; Physiotherapy Evidence Database (PEDro) [www.pedro.fhs. usyd.edu.au]; Psychological database for Brain Impairment Treatment Efficacy (PsycBITE) [www.psycbite.com]; PsycINFO (1935 to 2012); PubMED; and Speech Pathology Database for Best Interventions and Treatment Efficacy (speechBITE) [www.speechbite.com]. We sought to update and amalgamate the findings of our 2013 original paper [3•]. Searches were supplemented by hand searching. The search was performed in March-July 2019. Search terms for investigation replicated the same search strategy as our original paper and were supplemented by contributing authors' knowledge of the field, e.g., names of new interventions published since 2012 to add to the search. We also searched for the intervention evidence about preventative treatments in the obstetric or neonatal period, given the considerable reduction in the incidence of cerebral palsy since our last publication.

Electronic databases were searched with OVID host software using PICOs search terms. The full search strategy is available from the authors on request.

\section{Inclusion Criteria}

Published studies about interventions for children with cerebral palsy or at risk of cerebral palsy fulfilling the following criteria were included:

\section{Type of Study}

First, systematic reviews were preferentially sought [10]. Where multiple systematic reviews existed and newer evidence superseded the findings of earlier evidence, GRADEs were assigned based on the most recent high-quality evidence. We also searched for randomized controlled trials published after the latest systematic review, to account for new trials that might increase our confidence in the estimate of the treatment effect. For interventions where no systematic reviews existed, randomized controlled trials were preferentially sought, and where no randomized controlled trials existed, lower levels of evidence were included and appraised. New data (2012-2019) was then aggregated together with our data published in 2013 in order to review the entire evidence base. Second, retrieved bodies of evidence were appraised using the GRADE and 
Evidence Alert Traffic Light System using two independent raters, with unanimous agreement. GRADE is the evidence rating system endorsed by the World Health Organization [5, 6]. GRADE rates both (1) the quality of the evidence on a 4point continuum of High-Moderate-Low-Very Low. Randomized trials start at a score of $4 / 4$ (High) and can be downgraded based on methodological flaws; observational studies start at a score of $2 / 4$ (Low) but can be upgraded based on methodological strengths or downgraded if methodological flaws exist; and (2) the strength of the recommendation for use, which weighs up the balance between the benefits and harms, the resource usage' cost effectiveness, health equity, acceptability to consumers, and implementation feasibility [5]. When available, published outcomes of benefits were used to inform the strength of the recommendation. If no published literature was available, expert opinion was used. Recommendations were developed by the panel using the GRADE updated Evidence to Decision framework [5]. The Evidence Alert Traffic Light System was also applied to assist clinicians in obtaining clear, clinically useful answers within minutes [6]. The Evidence Alert uses a three-level traffic light color coding that recommends a course of action for implementation of the evidence within clinical practice. Green means go, because high-quality evidence from RCTs and systematic reviews indicates intervention effectiveness. Red means stop, because high-quality evidence from RCTs and systematic reviews indicates ineffectiveness or harm. Yellow means measure clinical outcomes, because either (i) promising evidence suggests possible effectiveness, but more research would increase our confidence in the estimate of the effect; or (ii) no research exists and therefore effects are unknown; or (iii) conflicting findings exists and therefore it is unclear how a patient might respond.

\section{Types of Intervention}

Studies that involved the provision of intervention either by a medical practitioner, an allied health professional, or an alternative and complementary medicine practitioner.

\section{Types of Participants}

Studies that explicitly involved human subjects. In the cerebral palsy preventative treatments evidence base, the participants were pregnant mothers or neonates. In the intervention evidence base, the participants were children living with cerebral palsy, in which $>25 \%$ of the participants had a diagnosis of cerebral palsy. We used a low cut off because many allied health interventions are provided using the exact same approach across multiple diagnostic groups (e.g., dysphagia management for stroke, brain injury, and cerebral palsy). We did not want to overlook important evidence that had been shown feasible and efficacious in the cerebral palsy population that was published within mixed population studies.

Studies were excluded from the review if (a) they were diagnostic, prognostic, or instrumentation studies; (b) they had lower levels of evidence, unless no systematic review or clinical trial had been published; (c) participants were adults; (d) they reviewed generic preventative interventions, e.g., good parenting; (e) they reviewed an entire discipline (e.g., physiotherapy, occupational therapy, speech pathology) and did not specify or sub-analyze individual named interventions but rather aggregated them together; (f) a second publication of the same study published the same results or participants; and/or ( $\mathrm{g}$ ) studies were unpublished or non-peer reviewed.

\section{Data Abstraction}

A data abstraction sheet based on the Cochrane's recommendations was used [8]. Abstracts identified from searches were screened by two independent raters to determine eligibility for further review. Abstracts were retained for full review if they met the inclusion criteria or if more information was required from the full-text to confirm the study met all eligibility criteria. Two independent reviewers then reviewed full-text versions of all retained articles and all additional articles identified by hand searching. Full-text articles were retained if they met inclusion criteria. Agreement on inclusion and exclusion assignment of the full-text articles was unanimous. Data extracted from included studies comprised citations, domains of impact of the intervention, level of the International Classification of Disability and Function (ICF) the intervention was aimed at, participants, study design, and dose. All the data required to answer the study questions were published within the papers, so no contact with authors was necessary.

\section{Ethics and Registration}

The study did not involve contact with humans, so the need for ethical approval was waived by the Cerebral Palsy Alliance's Human Research Ethics Committee. This systematic review was not registered.

\section{Results}

One thousand five hundred eighty-four citations were identified using the search strategy, of which 247 articles met the inclusion criteria for review $[9 \bullet \bullet, 10,11 \bullet, 12-248]$. The study flow is summarized in the PRISMA diagram (Fig. 1) [249].

We identified 182 interventions using our search strategy, an increase of 118 interventions from our 2013 review. Of these interventions, $41 / 182(23 \%)$ were strategies aiming to prevent cerebral palsy and 141/182 (77\%) were interventions aiming to manage cerebral palsy. The prevention strategies 
Fig. 1 Flow diagram of included articles

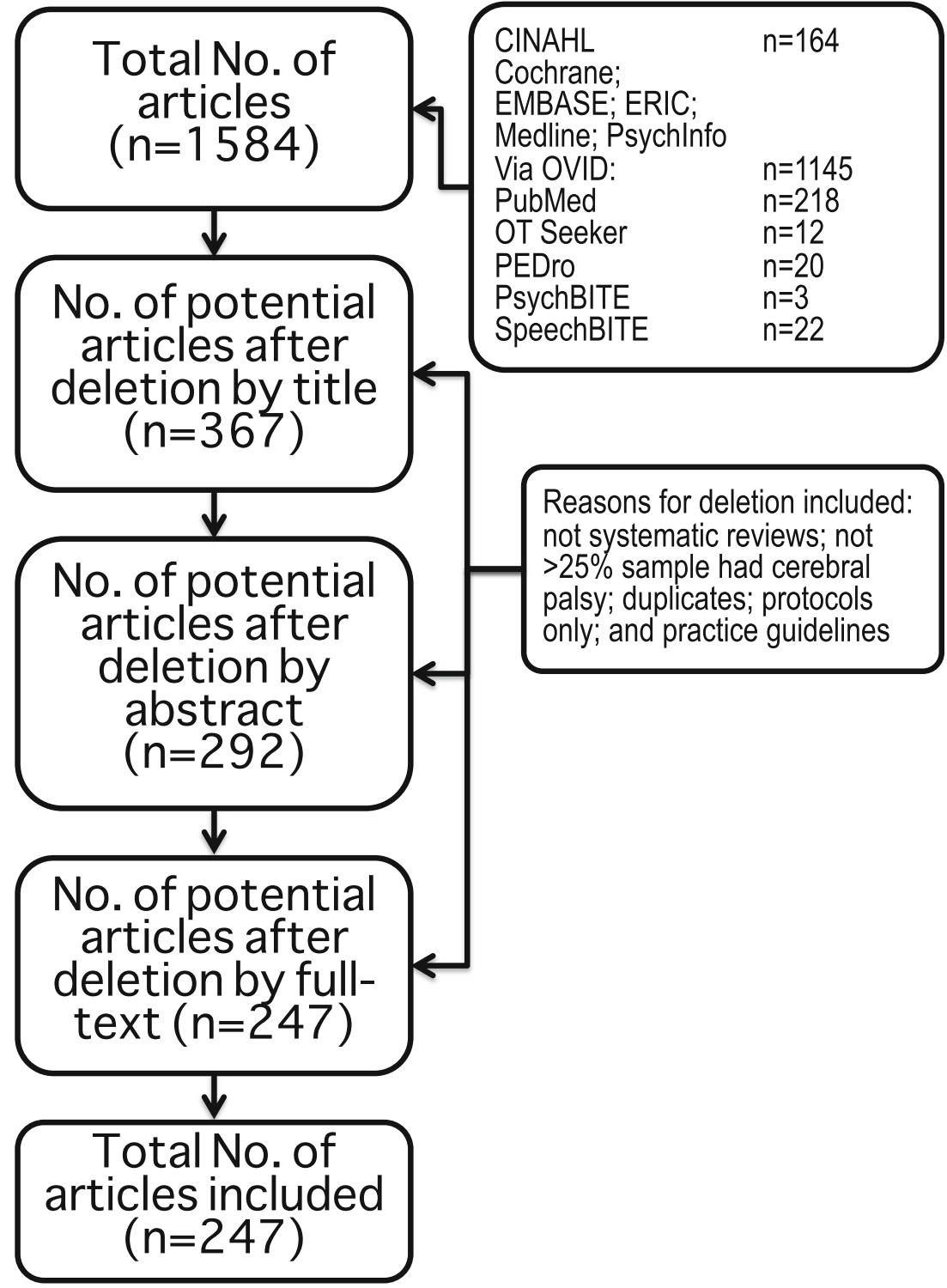

were categorized into antenatal prevention strategies (11/41, $27 \%$ ) and neonatal prevention strategies (30/41, 73\%). The interventions were categorized into allied heath interventions (83/141, 59\%), pharmacological interventions $(25 / 141,18 \%)$, surgical interventions $(19 / 141,13 \%)$, regenerative medicine interventions $(4 / 141,3 \%)$, and complementary and alternative medicine $(10 / 141,7 \%)$. From these 182 interventions, we identified 393 intervention outcome indicators that had been studied in children with cerebral palsy. In five indications, two separate gradings were assigned, because the quality of the evidence was different in two sub-populations (e.g., ambulant versus non-ambulant) for the same intervention aim. This took the GRADE count by indication to a total of 398 indications.

Some of the included systematic reviews had already conducted quality ratings on the body of evidence using the GRADE system. As per the GRADE process, we confirmed whether or not we agreed with these findings and also carried out assignment of GRADE coding for all other included papers. Across the 398 intervention outcomes, the GRADE ratings were as follows: $14 \%$ of outcomes assessed (54/398) were graded "do it" (i.e., Green light, go interventions); 66\% (264/398) were graded "probably do it" (i.e., Yellow light, weak positive); $17 \%$ (68/398) were graded "probably don't do it" (i.e., Yellow light, weak negative); and 3\% $(n=12 /$ 398) were graded “don't do it" (i.e., Red light, stop interventions).

Each intervention was coded using the ICF by the intervention's desired outcome. Out of the 383 intervention outcomes for children with CP identified in this study, $n=241 / 383$ $(62 \%)$ were aimed at the body structures and function level; $n=49 / 383$ (13\%) were aimed at the activity level; $n=12 / 383$ $(3 \%)$ were aimed at the participation level; $n=11 / 383(3 \%)$ were aimed at the environmental factors level; $n=1 / 383(<$ $1 \%$ ) were aimed at the personal factors level; $n=58 / 383$ 
$(15 \%)$ were aimed at a combined body structures and activities level; and $n=11 / 383(3 \%)$ were aimed at a combined activities and participation level.

\section{Participants}

This study included participants with cerebral palsy, a complex and heterogeneous condition. We included studies involving any motor sub-type [spastic, dyskinetic, or ataxic], any topography [hemiplegic/unilateral, diplegic/bilateral, or quadriplegic/ bilateral], and any functional ability level [Gross Motor Function Classification System (GMFCS) levels I-V and Manual Ability Classification System (MACS) levels I-V $[250,251]]$. In the detailed supplementary extraction table (Online Resource, Table 1), we noted which interventions had been tested in the various sub-groups and severities.

The main results are detailed in the online table, which outlines the citation, the name of the intervention, the intervention indicator, the types of participants the intervention had been tested on, the dose/intensity used within the research studies, the GRADE ratings, the panels reflections on the evidence to decision recommendation process, and the clinical nuance of findings and considerations for interpretation. We strongly urge readers to read the detailed online resource to gain the necessary specifics for understanding the evidence base.

To provide a summary of the online table and to assist with comparative clinical decision-making amongst intervention options for the same desired outcome, we mapped the interventions that seek to provide analogous outcomes, using bubble charts. In the bubble charts, the name of the circle is the intervention, and the italics under the title is the outcome measured and obtained. The size of the circle correlates to the volume of published evidence. The circle size was calculated by the amount and quality of evidence published. Bubble size 1, observational studies (OBS) only; size 2, 1-3 RCTs; size 3, 4-15 RCTs; and size 4, 15+ RCTs. The location of the circle on the $y$-axis of the graph corresponds to the GRADE system rating and estimate of effect (i.e., no effect was placed close to the worth it line, whereas a large treatment effect was placed further away from the worth it line). The color of the circle correlates to the Evidence Alert System (Fig. 2).

\section{Discussion}

High levels of evidence exist in the literature summarizing effective preventive strategies and intervention options for children with cerebral palsy. There was an exponential increase in the number of systematic reviews and clinical trials published about cerebral palsy interventions since our last review. We observed a substantial increase in the number of systematic reviews published about acupuncture, pharmacological agents for managing tone, orthopedic surgery, dysphagia management, physical activity, participation, and clinical trials in regenerative medicine.

\section{Prevention of Cerebral Palsy}

Undoubtedly, the most notable breakthroughs in the field of cerebral palsy research in the last decade have been made in the area of prevention $[9 \cdot \bullet, 10,11 \bullet, 12-18]$. The rate of cerebral palsy has fallen by $30 \%$ in some high-income countries, bringing the prevalence down to 1.4 per $1000[1,2]$. Babies born preterm constitute $43 \%$ of all cerebral palsy [2]. Antenatal magnesium sulfate before delivery of an infant less than 30 weeks' gestation prevents $30 \%$ of cerebral palsy (green light) [9]. Antenatal corticosteroids decrease intracranial hemorrhage and thereby also act as an effective neuroprotectant (green light) and have become the standard of care [9]. More research would increase our confidence in the estimate of the effect, but further trials are not feasible as it would be unethical to withhold antenatal corticosteroids in premature birth. Once an infant is born preterm and is mechanically ventilated, prophylactic caffeine (methylxanthines) prior to extubation effectively prevents cerebral palsy (green light) [11••]. For babies born at term with neonatal encephalopathy or asphyxia, therapeutic hypothermia commenced within 6-h of delivery is neuroprotective and prevents $15 \%$ of cerebral palsy associated with intrapartum hypoxia (green light) [11••]. There is now a pressing ethical imperative to translate prevention breakthroughs and a range of public health initiatives from high-income countries to low-income and middle-income countries, where the disease burden is high [252]. For example, in Bangladesh, the rate of cerebral palsy is more than double that of Australia (3.4 versus 1.4 per 1000). Twice as many Bangladeshi children have severe motor impairments (GMFCS IV-V = 43.6\%, compared with $26 \%$ in Australia), and $78.2 \%$ do not receive any rehabilitation [252]. Delayed umbilical cord clamping is also under investigation. As yet there is no specific data pertaining to whether delayed clamping prevents cerebral palsy, but we anticipate this will change in the near future and clinicians should stay abreast of this evidence base.

In recent years, our understanding of the genetic basis for cerebral palsy has advanced substantially [253]. A genetic contribution is likely in one-third of all children with cerebral palsy, especially in those without traditional risk factors such as prematurity and hypoxia [253]. As our understanding of neurobiology and genomics expands, the revolutionized field will result in the development of new prevention and treatment targets [253]. Experts also predict that future neuroprotective interventions will take advantage of trimester-specific brain development knowledge and that development of novel treatments will be informed by advances in biomarkers of brain injury, genetics, and neuroimaging [254]. 

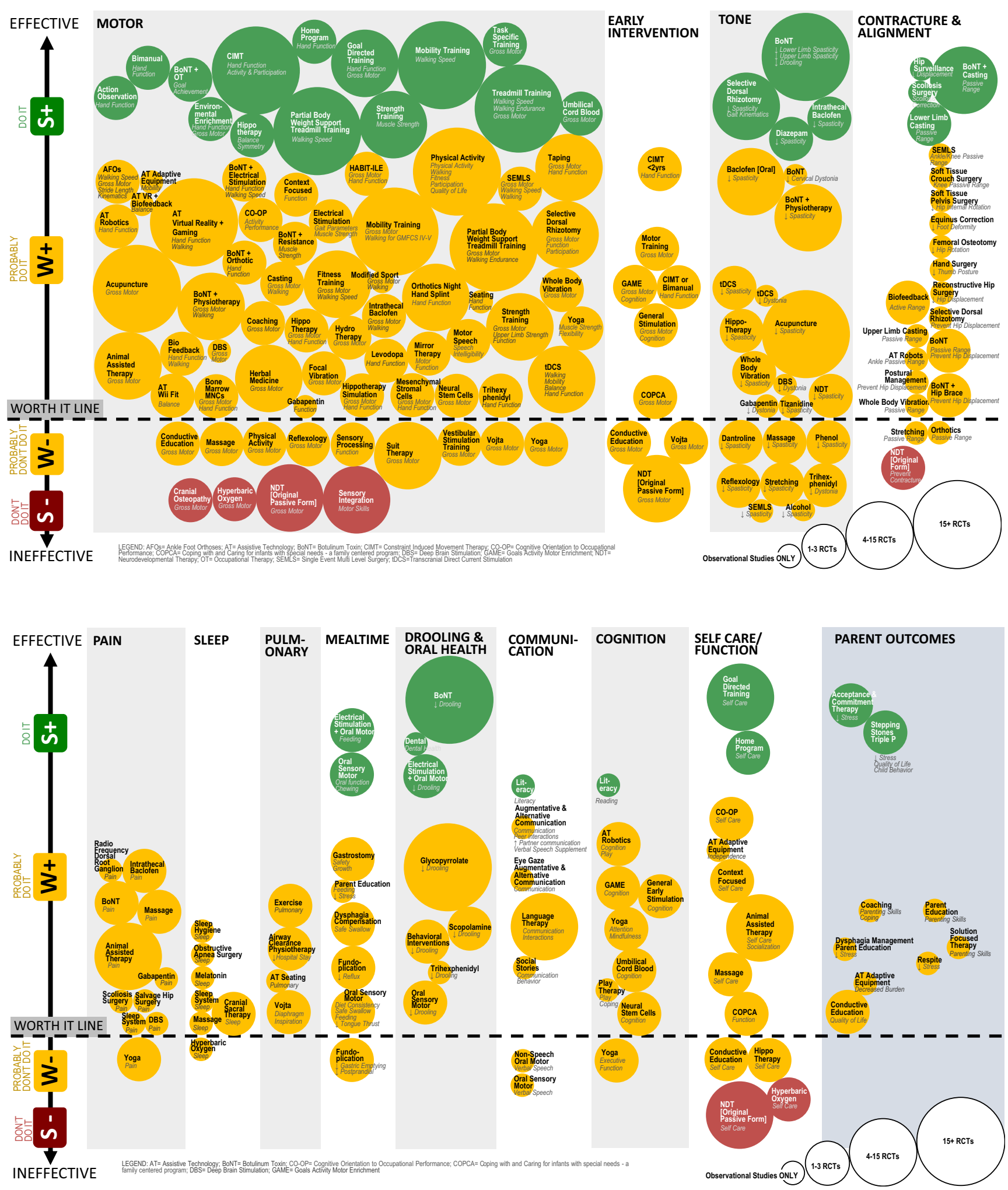

Fig. 2 Evidence Alert System. AFOs ankle-foot orthoses, AT assistive technology, BoNT botulinum toxin, CIMT constraint-induced movement therapy, CO-OP cognitive orientation to occupational performance, COPCA coping with and caring for infants with special needs-a family centered program, DBS deep brain stimulation, GAME goals activity motor enrichment, NDT neurodevelopmental therapy, OT occupational therapy, SEMLS single-event multi-level surgery, tDCS transcranial direct current stimulation 


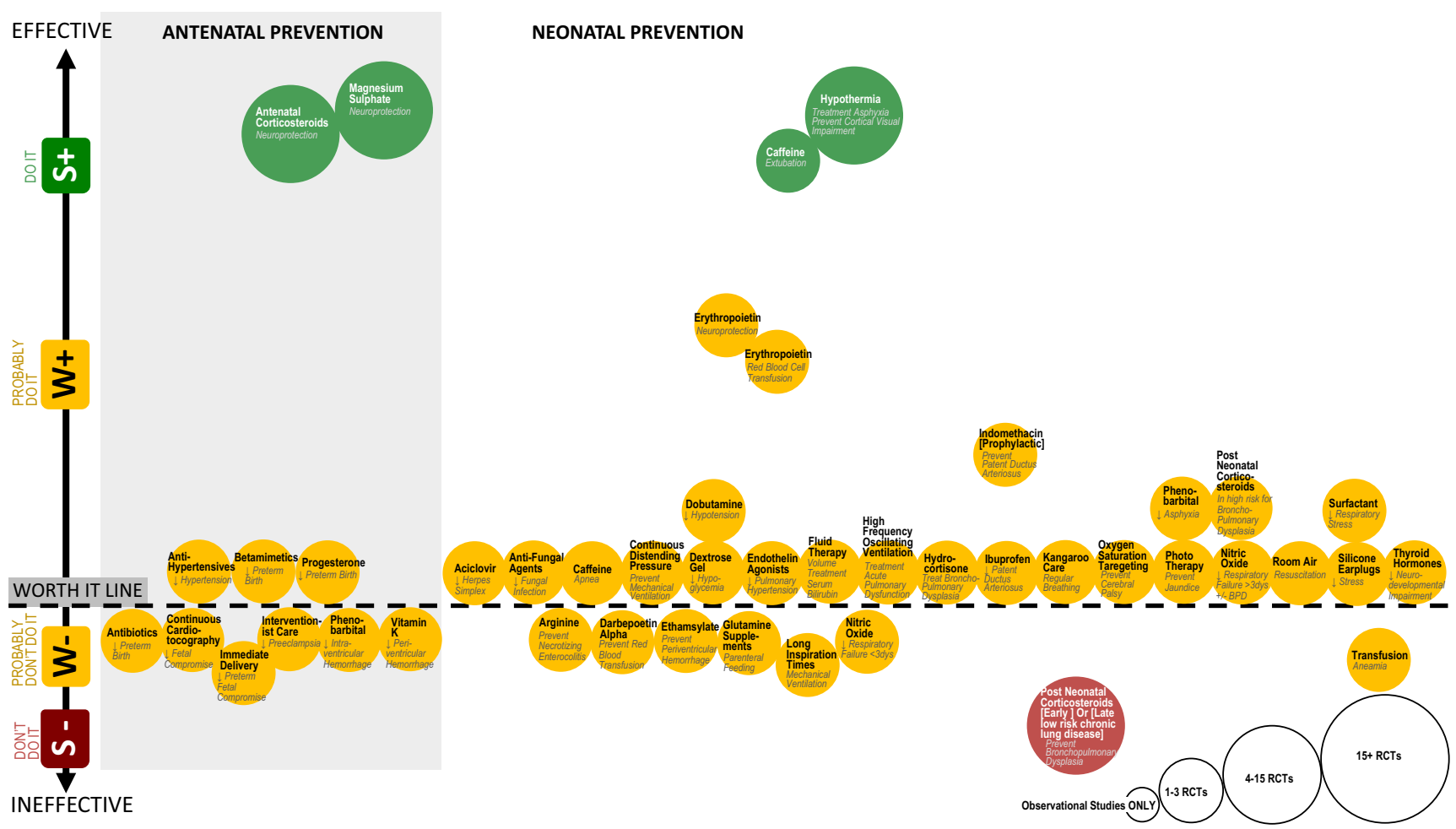

Fig. 2 continued

The field has also started to critically examine whether repair of a brain injury might be possible using regenerative medicine treatments, paving the way towards finding a cure. Our review found that erythropoietin has promising effects as a neuroregenerative treatment in the preterm population (yellow light, weak positive) and erythropoietin trials are underway in a population with hypoxic ischemic encephalopathy [11••]. In addition, there is now moderate-quality evidence that umbilical cord blood as a cell therapy, coupled with rehabilitation, is slightly more effective than rehabilitation alone for improving motor skills in children with cerebral palsy (green light) [221, 222]. The lack of legislation allowing access to autologous (patient's own) and/or matched allogeneic (donor) cord blood makes the feasibility of this treatment challenging.

\section{Management of Cerebral Palsy}

An intervention may target multiple desirable treatment outcomes, e.g., reduction of spasticity and improvement in function, and thus outcomes and levels of evidence could vary between outcomes. For most instances, the treatment outcome matched with the appropriate mechanism of action, e.g., pharmacological agent to reduce spasticity effectively reduced spasticity. There was often less convincing evidence (both in quality and volume) to support upstream effects for other treatment outcomes for other levels of the ICF, e.g., improvement in functional mobility. These are not surprising results; however, they provide an important reminder to clinicians to select interventions that address a child's specific goal based on the intervention's mechanism of action. Also, to be cognizant that applying more than one intervention simultaneously might be beneficial to achieve a goal where multiple goal-limiting factors are present. If the goal is to improve functional mobility: a pharmacological agent to reduce background spasticity (green light) [185] might make it easier to learn to move. Similarly, increasing lower limb muscle strength via strength training (green light) may improve related strength and endurance [151, 152], but principally targeted functional mobility training intervention will be required to establish an improvement in functional mobility (green light) [123, 127]. In all likelihood, the outcomes will be better if a combination of interventions are used. Some families believe that certain therapeutic approaches work for their child, but this was not possible to address within this review; however, we do not dismiss their views.

\section{Motor Interventions}

All children with cerebral palsy have, by definition, a motor impairment and difficulties with tasks involving motor performance [255]. In high-income countries, severity is lessening, and the rate of co-occurring epilepsy and intellectual disability is falling [2]. Three in four will now walk [2]. This decline in severity is encouraging. Children with cerebral palsy may be more likely than ever to be treatment responsive to motor 
interventions, because smaller brain injuries result in improved baseline motor, sensory, and perceptual skills and learning capabilities. Thus, understanding current evidence for effective motor interventions is critically important. There is now a clear dichotomy in the evidence base for what works and what does not for improving function and performance of tasks. Substantive clinical trial data support the efficacy of training-based interventions, including action observation training [20,21], bimanual training [54-56], constraintinduced movement therapy [46, 62-67], functional chewing training [137], goal-directed training [98], home programs using goal-directed training [112], mobility training [123, 127], treadmill training [65, 123, 127], partial body weight support treadmill training [123, 127, 169], and occupational therapy post botulinum toxin [190] (green lights). Moreover, environmental enrichment to promote task performance is effective (green light) [95] and adapting the environment and task to enable task performance via context-focused therapy (yellow light) [77] is a potent modulator of effective care. All these interventions have the following features in common: practice of real-life tasks and activities, using self-generated active movements, at a high intensity, where the practice directly targets the achievement of a goal set by the child (or a parent proxy if necessary). The mechanism of action is experience-dependent plasticity [256]. Motivation and attention are vital modulators of neuroplasticity, and successful task-specific practice is rewarding and enjoyable to children, producing spontaneously regular practice [256]. In stark contrast, bottom-up, generic, and/or passive motor interventions are less effective and sometimes clearly ineffective for improving function and movement for children with cerebral palsy. These include craniosacral therapy [239-241], hyperbaric oxygen [234, 235], neurodevelopmental therapy in the original passive format [108, 129-132], and sensory integration [3] (red lights). When viewed through the lens of neuroplasticity, these results are logical. A passive experience of a movement, provided via a hands-on therapeutic approach from a carer or therapist, does not involve any child-initiated problem solving or any child activation of their motor circuity.

There are also several adjunctive interventions that when combined with task-specific motor training may augment the positive effects of training. These include electrical stimulation [65, 92-94], hydrotherapy [108, 110, 111], taping [159-164], transcranial direct current stimulation [101, 166-168], and virtual reality serious gaming [33-47] (yellow lights, weak positive). These interventions warrant more research as children reported finding gaming interventions rewarding and normalizing, and preferred electrical stimulation to wearing ankle-foot orthoses from a comfort perspective [93]. Also, taping is better tolerated than traditional orthotics with children often reporting discomfort and dissatisfaction with these interventions or disliking the cosmetic effect [73,
140]. Other benefits from these adjunctive interventions include cardiorespiratory fitness and social integration, and the importance of which cannot be underestimated. Adjunctive suit therapy does not appear to have any additive benefit over and above motor training $[156,157]$. Some children experience respiratory compromise, overheating, and peripheral cyanosis which resolve after removing the suit (yellow light, weak negative) $[156,157]$. Suit therapy is therefore not recommended as a front-line treatment, or stand-alone treatment, nor should it be unsupervised $[156,157]$. However, it is very important to recognize that for some families, the process and routine of donning a suit may mean they engage in more intensive therapies and active practice, which may produce positive results. We know that intensive task-specific motor practice is effective and works in a variety of treatment modalities [98]. The theory behind transcranial direct current stimulation having an augmentative effect to motor training, through provision of an additional targeted stimulation of the motor cortex, is logical, and more research is warranted [166-168].

The available studies about complementary and alternative medicine interventions for childhood cerebral palsy aimed to improve motor skills. Trials suggested efficacy with acupuncture [227, 228] and animal-assisted therapy [102] (yellow lights, weak positive). In contrast, conductive education [231, 232], massage [238], reflexology [243], Vojta [244-246], and Yoga [248] were probably ineffective for improving motor skills (yellow lights, weak negative), and cranial sacral osteopathy [239-241] and hyperbaric oxygen [234] showed no between-group differences for motor skills in moderatequality trials and serious side effects occurred (red lights). Proponents of conductive education would claim that because the approach is holistic, that it is not reasonable to analyze indicators in isolation; nevertheless, these are the motor outcome results from published clinical trials. It is therefore important to note, conductive education may have benefits for social skills and quality of life outcomes [231]. The manual therapies, including massage (green light) [237] and cranial sacral osteopathy [241] and reflexology [243] (yellow lights, weak positive), appeared to help reduce constipation. Massage also appeared to help reduce pain [3•] (yellow light, weak positive), whereas Yoga did not [248] (yellow light, weak negative). However, Yoga did appear to improve attention, muscle flexibility, and balance (yellow light, weak positive) [248].

\section{Tone Management}

Eighty-five percent of children with cerebral palsy have spasticity as their primary motor type and $7 \%$ have dyskinesia (including either dystonia or athetosis) as their primary motor type [2]. Many children have a mixed presentation involving both motor types [2]. Spasticity and dystonia cause 
involuntary movements and postures that affect motor control and can be painful. Our review identified that the following pharmacological agents and neurosurgical procedures effectively reduce spasticity: botulinum toxin [185], intrathecal baclofen [175, 176], diazepam [3•], and selective dorsal rhizotomy [209] (green lights), plus dantrolene [3•] and tizanidine [3•] are probably effective (yellow light). Supplementary local injections of alcohol probably reduce spasticity [3] (yellow light, weak positive), and local injections of phenol also probably reduce spasticity very shortterm, but side effects are common (yellow light, weak negative) [195]. Less research involves dystonia management, given the lower prevalence and under-recognition of this motor disorder. Probably effective pharmacological agents for reducing dystonia include local injections of botulinum toxin [3•], oral gabapentin [193], intrathecal baclofen via a pump [177] (yellow light, weak positive), and oral trihexyphenidyl, which may reduce dystonic and athetoid involuntary movements and improve participation, but side effects may outweigh the benefits for some children (yellow light, weak negative) [177, 196]. There is as much art as there is science to prescribing pharmacological agents, especially for children with cerebral palsy that have multiple medical comorbidities. For example, in a child with combined dystonia and epilepsy, may benefit from using one medication that addresses both symptoms such as gabapentin, instead of two medications targeting the symptoms individually. Additionally, botulinum toxin [187], intrathecal baclofen [179, 180], and gabapentin [179] appear to reduce pain (yellow light, weak positive), which may further support the clinical decision to trial these agents, despite this not being the primary mechanism of these agents, as the multiple benefits may make them an acceptable intervention to children and parents. Deep brain stimulation appeared promising for children with dystonia that caused pain and severely limited daily participation and more research is warranted [177, 198].

Against the backdrop of spasticity management, there is a now an intense research focus on improved understanding of pathology, histochemistry, and muscle architecture in cerebral palsy [257]. Children with cerebral palsy appear to have elevated proinflammatory cytokines and genes involved in the extracellular matrix of their skeletal muscles, combined with increased intramuscular collagen and reduced ribosomal production [258]. Newer understandings of these pathophysiological muscle changes have led some clinicians to call for a reconsideration of botulinum toxin treatment, which induces therapeutic weakness and potential muscle fibrosis [259]. We do not yet know whether the observed atrophy and insertion of replacement fat and connective tissue observed in muscles of children with cerebral palsy is the result of a direct or accelerated adverse event from botulinum toxin or whether these changes are the natural history of cerebral palsy. We anticipate that more research into muscle pathology will both alter treatment recommendations over time and, more importantly, lead to the discovery of new interventions.

\section{Contracture Prevention and Management}

Contracture is a common complication, particularly for children with spastic cerebral palsy. A longitudinal population-based study in Sweden has demonstrated that comprehensive multidisciplinary intervention at the right time can prevent contracture [260]. Contracture prevention and management should be thought of as a continuum, which will now be described. (a) In the early years, experts recommend high intensity selfgenerated active movement to prevent the onset of weakness, disuse and contracture [261]. While no clinical trial data is currently published supporting this idea, the hypothesis is currently being tested in clinical trials. (b) In Sweden, before contracture develops, the following interventions are used as part of comprehensive care: active movement, standing in standing shells (custom molded standing frames) for children GMFCS IV-V, and spasticity management using botulinum toxin where indicated. (c) Our review has shown that once a contracture has begun to develop, serial casting can be applied to effectively reduce or eliminate early/moderate contractures in the short term (green light). Notably, the skill of the practitioner in correctly aligning the joint and applying the cast is known to affect the result. For example, it is possible to perceive that increased range of motion has been achieved from casting, when in fact a further loss of biomechanical alignment of the midfoot (known as a midfoot break) has been induced, with no improvements in the hind foot. Casting effects can be enhanced by applying casts four weeks after botulinum toxin injections when the spasticity has been reduced (green light). Data indicates that children tolerate casting better when it is applied four weeks post toxin injection rather than immediately. The secondary weakness and altered proprioception induced from casts (with or without botulinum toxin) must be considered. Emergent evidence suggests that changing the casts at 3-day intervals rather than weekly intervals can shorten the total duration of the casting series and thus lower the amount of weakness induced. After casting, active strength training [60] (green light) and goal-directed training [98] (green light) are recommended to make functional use of the new range gained. (d) Once a contracture is severe (e.g., greater than $20^{\circ}$ ) and longstanding, casting will no longer be sufficient in isolation, and orthopedic surgery requires consideration. Some children and some muscles do not ever respond well to casting and proximal muscles cannot ever be cast; thus, surgical decision-making will be different in these scenarios. Moreover, casting requires regular appointments at specialist centers which may not be feasible for families in rural and remote locations. Orthopedic surgery may also be considered well before a contracture is severe, in order to maintain alignment, muscle length, and optimize biomechanics. The treating surgeon will consider the clinical examination, functional level, 
and child's age, optimizing the timing of the surgery and minimizing the number of repeat procedures they will need over a childhood. Biomechanically, all joints in the lower limb work together in gait, meaning surgical lengthening of muscles at one joint impacts available range and control at other joints. Therefore, single-event multi-level surgery is a powerful intervention to simultaneously address the biomechanics of gait and minimize repeat surgeries (yellow light) [216, 217]. Our review has shown that traditional interventions for contracture management, including neurodevelopmental therapy [3•] (red light) and passive stretching in isolation [155] (yellow light), appear ineffective and the panel assigned negative recommendations since effective substitutes exist. In contrast, we found emergent low-quality evidence suggesting ankle robotics [32], biofeedback [30], botulinum toxin plus electrical stimulation [190], and whole-body vibration [97] may help manage contracture, by eliciting antagonist muscle activity that counterbalance involuntary agonist muscle contractions (yellow light), though more research is needed in this area.

\section{Hip Surveillance}

One in three children in high-income countries experience progressive hip displacement as a complication of their cerebral palsy, except in the Nordic countries where rates are substantially lower $[260,262]$. There is moderate-quality evidence and a strong recommendation to use comprehensive hip surveillance practices to facilitate early detection and management of hip displacement (green light). It may initially seem contradictory that hip surveillance is allocated a green light while the orthopedic and physiotherapy interventions designed to prevent hip displacement are coded yellow. This paper reports purely on the best available evidence, coded using the GRADE framework. We observe that interventions in isolation (including botulinum toxin, intrathecal baclofen, selective dorsal rhizotomy, obturator nerve blocks, positioning, and bracing) have small effect sizes for preventing hip migration [145, 147]. In contrast, important clues arise from longitudinal population-based studies in Sweden, which have shown that comprehensive multidisciplinary intervention (including botulinum toxin, weight-bearing, motor training, and orthopedic surgery) at the right time and the right dose can prevent hip dislocation [260]. We, therefore, conclude that management of the hip surveillance must be early, timely, and comprehensive, and clinical practice guidelines exist to inform and guide best management (https://www.ausacpdm. org.au/resources/australian-hip-surveillance-guidelines/).

\section{Physical Activity}

Physical activity is essential for improving health but designing and implementing moderate to vigorous exercise programs for children with severe physical disabilities, who have limited movement and move slowly, is complex [263]. Recommendations to concurrently increase moderate to vigorous physical activity and replace sedentary behavior with light physical activity have been proposed to improve health [263]. New trials indicate that physical activity interventions (including exercise, activity training, strength training, and behavioral change strategies) probably improve fitness [144], physical activity [142-144], ambulation [144], mobility [144], participation, and quality of life [142] (yellow lights, weak positive). However, they do not appear to improve gross motor skills (yellow light, weak negative) [96, 144].

\section{Participation}

We observed a shift in interventions that affected a child's participation within their community. Most importantly, we noticed that interventions had been developed since 2013, which were specifically designed to target participation, and address barriers that prohibit participation and their effects were being studied in trials underway [264]. In other words, the targeted participation intervention was acting directly at the participation level of the international classification of function. There was a shift away from anticipating nonparticipation-based interventions might confer participation gains upstream.

\section{Dysphagia Management}

Half of all children with cerebral palsy have dysphagia and the prevalence is even higher in the infant population [265]. One in 15 will require non-oral tube feeding [262]. Dysphagia management is extremely important because aspiration resulting in respiratory complication is a leading cause of death in individuals with cerebral palsy (45\%) [266]. Experts have called for greater attention to respiratory health given the lack of preventative strategies and low levels of evidence for management strategies (airway clearance techniques, oral sensorimotor therapy, compensatory strategies such as positioning and thickening fluids, sialorrhea management, upper airway interventions, antibiotics, gastro-intestinal interventions, and spinal surgery) (yellow lights) [22]. We identified two newer dysphagia management approaches in the evidence base which positively address feeding skills and potentially lower the risk of aspiration: (a) Electrical stimulation plus oral sensorimotor therapy conferred better lip closure during swallowing, the ability to swallow food without excess loss, the ability to sip liquid, the ability to swallow liquid without excess loss, and the ability to swallow without cough than sham electrical stimulation plus oral sensorimotor therapy (green light) [138]. No adverse effects were reported in the studies included in this review; however, immediate and longitudinal safety concerns have not yet been well documented. As such, given that this intervention approach yields only 
modest benefits above and beyond oral sensorimotor therapy alone, a considered approach is warranted within a pediatric population. (b) A new motor learning-based oral sensorimotor intervention called functional chewing training ( $\mathrm{FuCT}$ ) appeared to improve chewing and reduce tongue thrust and sialorrhea better than traditional oral sensorimotor treatment alone [137] (yellow light), suggesting the direct training component was important. The FuCT findings are consistent with current thinking about motor learning. However, it must be noted that FuCT uses a combination of direct interventions, utilizing food or fluid; indirect interventions, utilizing nonnutritive tools to develop chewing skills; and sensory stimulation such as passive massage. Translation of this principle within the dysphagia management evidence base is becoming more prominent. Further research that compares direct, indirect, sensory, and compensatory interventions would be helpful in determining which approach results in greater skill development.

\section{Early Interventions}

Rates of cerebral palsy following prematurity, encephalopathy, and neonatal surgery are well understood. It is now possible to accurately detect and diagnose cerebral palsy as early as three months of age (corrected), enabling much earlier intervention [267]. Previously only $61-64 \%$ of infants with cerebral palsy were referred for intervention before 12 months of age due to late diagnosis $[267,268]$. This directly affected the volume and methodological quality of early intervention clinical trials conducted and published for infants with cerebral palsy. An important turning point in the field was the publication of a systematic review identifying that child-active motor learning early interventions appeared to confer improved movement and cognition (yellow light, weak positive), whereas passive approaches such as neurodevelopmental therapy produce no better movement skills than untreated controls (yellow light, weak negative) [79, 80]. Recently, there has been a burst of small pilot trials conducted, testing the feasibility, acceptability, and preliminary efficacy of a range of novel motor learning training-based interventions adapted to be infant-friendly. These novel interventions (baby-CIMT [85], baby-bimanual [86], GAME [83, 84], small steps [82]) have reported positive gains in movement skills (yellow light, weak positive) confirming the findings of Morgan et al.'s (2016) systematic review [79]. More extensive replication trials are underway in these early interventions using rigorous designs with adequate statistical power, meaning more will be known in the next few years about the efficacy of motor learning training-based early intervention for cerebral palsy.

In contrast, the feasibility and preliminary efficacy trials of a novel parent coaching-based approach (COPCA) disappointingly did not confer any gains over and above passive neurodevelopmental therapy within traditional physiotherapy (yellow light, weak positive) [87-90]. Likewise, conductive education [91] and Vojta therapy [79, 80] for infants with cerebral palsy also appear ineffective for improving movement skills (yellow light, weak negative). Neither of these approaches are based upon motor learning theory, and thus seem to further confirm the findings of the pivotal systematic review which identified motor learning to be key [79]. Trials into early interventions targeting other developmental domains which can be affected in cerebral palsy including cognition, feeding, and communication will emerge in the near future.

\section{Cognitive Interventions}

Almost half of all children with cerebral palsy have cooccurring intellectual disability $(46 \%)$ of varying severities, but notably, the prevalence of this comorbidity declining [1, $2,262]$. Co-occurring intellectual disability, coupled with severe physical disability, is known to elevate the risk for premature death during childhood [266]. With the shift in thinking about early motor interventions, the field has also started to explore whether the cognition of children with cerebral palsy can be modified and optimized. Early interactive reading and participation in early education settings, such as preschool, is known to improve intelligence in the typically developing and social risk populations, especially if these interventions include specific language development components [269]. In the cerebral palsy field, there is a shift towards actively recommending and testing these cognitive interventions with children with cerebral palsy. Our review found newer evidence of literacy interventions tailored for children with cerebral palsy using communication devices were effective (green light) [117, 118]. Infants that received GAME intervention (a combination of motor training, environmental enrichment, and coaching) had better cognition at 1 year of age than age-matched peers on a norm-referenced test (yellow light, weak positive) [83, 84]. More research on enriching the cognitive skills of infants with cerebral palsy is warranted.

Another innovation has been to test the feasibility, acceptability, and preliminary efficacy of a cognitive-based intervention known as cognitive orientation to occupational performance (CO-OP) [270]. CO-OP was originally designed for the developmental coordination disorder population where dyspraxia is the most important clinical sign [270], but now has promising evidence of efficacy for cerebral palsy, especially the dystonic type where treatment options are lacking [73-76]. In CO-OP, children set their own goals and are guided to discover and individualize strategies for successfully carrying out their goals, via a global problem-solving strategy "goal-plando-check" [270]. Once the child has self-identified a successful strategy, they practice the real-life task at high intensity, similar to other motor learning approaches [98]. Four studies have now been conducted in the cerebral palsy population suggesting 
CO-OP improves function at a low dose and low cost with large effect sizes (yellow light, weak positive) [73-76]. The conduct of a definitive trial is warranted.

\section{Parent Interventions}

Parenting a child with cerebral palsy is known to be isolating and stressful. Supporting parents is essential both to optimize the child's development and to protect a parent's mental health. We observed that two interventions for parents of children with cerebral palsy, stepping stones triple P and acceptance and commitment therapy (ACT), now have empirical evidence of effectiveness (green lights) [19]. Stepping stones focuses on enhancing parenting skills and ACT focuses on increasing parental flexibility and enhancing a parent's ability to use their parenting skills in a stressful context [19]. The early and intentional support of parents offers important possibilities for improving children's outcomes.

\section{A Guide to Interpretation}

This paper is not the personal opinions of the authors; instead, it is a summary of the best available published evidence in 2019. This paper does not, therefore, invalidate observations of a child's response to interventions, even if they differ to average treatment responses measured in trials. Furthermore, it does not seek to criticize therapy choices of families or critique health care providers. Where evidence is not available, more well-designed trials are necessary. As cerebral palsy is a heterogeneous condition, the interpretation of the results from randomized controlled trials is complex.

Randomized controlled trials by their nature summarize the average response to an experimental treatment compared with that of a controlled comparison. In any given trial or realworld clinical scenario, an individual with cerebral palsy may respond better, or worse, than the average trial data. Heterogeneity is why many of the included trials have wide confidence intervals, indicating varied responses. We observed that often the trials with most robust treatment effects focused on homogeneous sub-groups of cerebral palsy (e.g., hemiplegia). In the future, alternative methodologies such as the $n$ of 1 trial may accommodate the issue of heterogeneity.

To use the findings of this paper within clinical practice, we recommend the following: First, ask the child and family to define intervention goals. Second, match their goals to the outcome indicator headings and look up the corresponding intervention options with the associated levels of evidence. Third, select the intervention with the highest level of evidence and explain to families that on average, $\mathrm{X}$ intervention is most likely to help someone achieve their goals, and offer it. Monitor the individual effects of the intervention for the goal.
Fourth, if the intervention is ineffective or unavailable, or the family declines (e.g., tried previously or side effects occurred), select the second most effective intervention and explain that on average, $\mathrm{Y}$ intervention is next most likely to help reach goals. Continue with this transparent conversation, compassionately acknowledging the disappointment if the child does not respond. Collectively problem solve a plan that matches the child's capabilities and optimizes inclusion.

\section{Study Limitations}

Our study has several limitations. First, a systematic review of systematic reviews is a study limitation in its own right because the methodology does not create any new knowledge that was not already published. In addition, the methodology of systematic reviews established by Cochrane favors the inclusion of randomized controlled trials, which may mean important observational studies are excluded or under-emphasized. Second, any summary lacks key details. Our helicopter view synthesis means that specific details about intervention fidelity, key ingredients, and best responders or non-responders are not reported or described in depth. We therefore advise clinicians and researchers to read additional literature to obtain this information, especially when adopting new interventions not previously used. Third, systematic reviews, despite being the highest level of evidence, are not without bias. Even though our review aimed to be unbiased, it included inherent biases. Publication bias may be at work within the included data we appraised, since trials with no between-group differences are less likely to be published in the first place, positively weighting the evidence base towards interventions that work. In addition, systematic reviews can be of varying methodological quality. Review authors may elect to include and review lower level evidence within their reviews to provide a more comprehensive picture of the evidence, but in doing so, provide a summary of highly biased data. We then have further summarized potentially biased data. The review authors may also have excluded relevant data, based on their inclusion criteria and the question they were seeking to answer. Fourth, in some of the included systematic reviews, we identified statistical errors, which we reinterpreted or reanalyzed where possible. For example, an accidental reversal of forest plots meaning the analysis was the opposite of the way the authors reported it. Another example was a misinterpretation of meta-analyses, where the confidence intervals around the standardized mean difference crossed the line of no effect, but the authors had made their interpretations based on the standardized mean difference alone and erroneously 
interpreted the intervention as effective. Fifth, despite our thorough search strategy, there is no guarantee that we retrieved and included all relevant systematic reviews, or important data published after the included reviews that might have changed our confidence in the estimate of the effects. Sixth, as we excluded articles not published in English and adhered to strict inclusion criteria regarding $\%$ of participants identified as having cerebral palsy, we may have overlooked important data and/or excluded recent reviews exploring relevant, non-CP-specific interventions (for example Augmentative and Alternative Communication) due to participant numbers not reaching the required threshold. Some of the studies included in the reviews have reported on cerebral palsy but that may not be the primary outcomes of those studies.

\section{Conclusion}

Our paper systematically describes the best available evidence for cerebral palsy interventions in 2019, and highlights areas for more research. We found compelling evidence from systematic reviews to suggest the following: Green light prevention strategies: antenatal corticosteroids, magnesium sulfate, caffeine, and hypothermia. Green light allied health interventions: acceptance and commitment therapy, action observations, casting, constraint-induced movement therapy, environmental enrichment, fitness training, goal-directed training, hippotherapy, home programs, literacy interventions, mobility training, oral sensorimotor, oral sensorimotor plus electrical stimulation, pressure care, stepping stones triple $\mathrm{P}$, strength training, taskspecific training, treadmill training, partial body weight support treadmill training, and weight-bearing. Green light medical, surgical, pharmacological, and regenerative therapy interventions: anti-convulsants, intrathecal baclofen, bisphosphonates, botulinum toxin, botulinum toxin plus occupational therapy, botulinum toxin plus casting, diazepam, dental care, selective dorsal rhizotomy, scoliosis correction, hip surveillance, and umbilical cord blood cell therapy. In the last six years, many additional interventions have been researched, and the following interventions have been upgraded from emergent (yellow) to effective (green): Botulinum toxin plus adjunctive casting for increasing range of motion; goal-directed training for improving gross motor skills; hippotherapy for increasing symmetry; stepping stones triple P for improving child behavior; and strength training for improving muscle strength. There is a lack of robust clinical efficacy evidence for a large proportion of the interventions in use within standard care for people with cerebral palsy, and more research would increase our confidence in the estimate of effect. Thus, we have highlighted the need for more research using rigorous methodologies to advance the evidence base about interventions for cerebral palsy, to better inform decision-making by families and clinicians.

\section{Compliance with Ethical Standards}

Conflict of Interest Dr. Novak and coauthors have nothing to disclose.

Human and Animal Rights and Informed Consent This article does not contain any studies with human or animal subjects performed by any of the authors

Open Access This article is licensed under a Creative Commons Attribution 4.0 International License, which permits use, sharing, adaptation, distribution and reproduction in any medium or format, as long as you give appropriate credit to the original author(s) and the source, provide a link to the Creative Commons licence, and indicate if changes were made. The images or other third party material in this article are included in the article's Creative Commons licence, unless indicated otherwise in a credit line to the material. If material is not included in the article's Creative Commons licence and your intended use is not permitted by statutory regulation or exceeds the permitted use, you will need to obtain permission directly from the copyright holder. To view a copy of this licence, visit http://creativecommons.org/licenses/by/4.0/.

\section{References}

Papers of particular interest, published recently, have been highlighted as:

- Of importance

- Of major importance

1. Galea C, McIntyre S, Smithers-Sheedy H, Reid SM, Gibson C, Delacy M, et al. Cerebral palsy trends in Australia (1995-2009): a population-based observational study. Dev Med Child Neurol. 2019;61(2):186-93.

2. Register ACPR. Report of the Australian Cerebral Palsy Register: birth years 1995-2012. November 2018.

3. Novak I, McIntyre S, Morgan C, Campbell L, Dark L, Morton N, et al. A systematic review of interventions for children with cerebral palsy: state of the evidence. 2013. p. 885-910. This overview systematic review provides a summary of best available evidence for interventions that treat and manage cerebral palsy up to 2013.

4. Grol R, Grimshaw J. From best evidence to best practice: effective implementation of change in patients' care. Lancet (London, England). 2003;362(9391):1225-30.

5. Alonso-Coello P, Schünemann HJ, Moberg J, BrignardelloPetersen R, Akl EA, Davoli M, et al. GRADE Evidence to Decision (EtD) frameworks: a systematic and transparent approach to making well informed healthcare choices. 1: Introduction. BMJ. 2016;353:i2016.

6. Novak I, McIntyre S. The effect of education with workplace supports on practitioners' evidence-based practice knowledge and implementation behaviours. In: Shepherd RB, editor. . Oxford, England: Elsevier Health Sciences; 2010.

7. Smith V, Devane D, Begley CM, Clarke M. Methodology in conducting a systematic review of systematic reviews of healthcare interventions. BMC Med Res Methodol. 2011;11(1): 15 .

8. Cochrane handbook for systematic reviews of interventions. Higgins JPT, Green S, editors. Chichester, England ;: WileyBlackwell; 2008. 
9.• Shepherd E, Salam RA, Middleton P, Makrides M, Mcintyre S, Badawi N, et al. Antenatal and intrapartum interventions for preventing cerebral palsy: an overview of Cochrane systematic reviews. J Paediatr Child Health. 2017;53(Supplement 2):90 This Cochrane review provides an in-depth summary of the effectiveness of obstetric interventions for preventing cerebral palsy.

10. Neilson JP, West HM, Dowswell T. Betamimetics for inhibiting preterm labour. Cochrane Database Syst Rev. 2014;2:CD004352.

11.• Shepherd E, Salam RA, Middleton P, Han S, Makrides M, McIntyre S, et al. Neonatal interventions for preventing cerebral palsy: an overview of Cochrane systematic reviews. Cochrane Database Syst Rev. 2018;6:Cd012409 This Cochrane review provides an in-depth summary of the effectiveness of neonatal interventions for preventing cerebral palsy.

12. Chorna OD, Guzzetta A, Maitre NL. Vision assessments and interventions for infants 0-2 years at high risk for cerebral palsy: a systematic review. Pediatr Neurol. 2017;76:3-13.

13. Baud O, Trousson C, Biran V, Leroy E, Mohamed D, Alberti C. Association between early low-dose hydrocortisone therapy in extremely preterm neonates and neurodevelopmental outcomes at 2 years of age. JAMA: J Am Med Assoc. 2017;317(13): 1329-37.

14. Fischer HS, Reibel NJ, Buhrer C, Dame C. Prophylactic early erythropoietin for neuroprotection in preterm infants: a meta-analysis. Pediatrics. 2017;139(5).

15. Lai MN, Ahmad Kamar A, Choo MY, Kong YJ, Ngim FC. Fluid supplementation for neonatal unconjugated hyperbilirubinaemia. Cochrane Database Syst Rev. 2017;8.

16. Conde-Agudelo A, Diaz-Rossello JL. Kangaroo mother care to reduce morbidity and mortality in low birthweight infants. The Cochrane database of systematic reviews. 2016(8):Cd002771.

17. Askie LM, Darlow BA, Finer N, Schmidt B, Stenson B, TarnowMordi W, et al. Association between oxygen saturation targeting and death or disability in extremely preterm infants in the neonatal oxygenation prospective meta-analysis collaboration. JAMA: J Am Med Assoc. 2018;319(21):2190-201.

18. Askie LM, Darlow BA, Davis PG, Finer N, Stenson B, Vento M, et al. Effects of targeting lower versus higher arterial oxygen saturations on death or disability in preterm infants. Cochrane Database of Systematic Reviews. 2017;2017 (4) (no pagination)(CD011190).

19. Whittingham K, Sanders MR, McKinlay L, Boyd RN. Parenting intervention combined with acceptance and commitment therapy: a trial with families of children with cerebral palsy. J Pediatr Psychol. 2016;41(5):531-42.

20. Buccino G, Arisi D, Gough P, Aprile D, Ferri C, Serotti L, et al. Improving upper limb motor functions through action observation treatment: a pilot study in children with cerebral palsy. Dev Med Child Neurol. 2012;54(9):822-8.

21. Sgandurra G, Ferrari A, Cossu G, Guzzetta A, Fogassi L, Cioni G. Randomized trial of observation and execution of upper extremity actions versus action alone in children with unilateral cerebral palsy. Neurorehabil Neural Repair. 2013;27(9):808-15.

22. Blackmore AM, Gibson N, Cooper MS, Langdon K, Moshovis L, Wilson AC. Interventions for management of respiratory disease in young people with cerebral palsy: a systematic review. Child Care Health Dev. 2019.

23. Betancourt JP, Eleeh P, Stark S, Jain NB. Impact of ankle-foot orthosis on gait efficiency in ambulatory children with cerebral palsy: a systematic review and meta-analysis. Am J Phys Med Rehabil. 2019.

24. Lintanf M, Bourseul JS, Houx L, Lempereur M, Brochard S, Pons C. Effect of ankle-foot orthoses on gait, balance and gross motor function in children with cerebral palsy: a systematic review and meta-analysis. Clin Rehabil. 2018;32(9):1175-88.
25. Aboutorabi A, Arazpour M, Ahmadi Bani M, Saeedi H, Head JS. Efficacy of ankle foot orthoses types on walking in children with cerebral palsy: a systematic review. Ann Phys Rehab Med. 2017;60(6):393-402.

26. Angsupaisal M, Maathuis CG, Hadders-Algra M. Adaptive seating systems in children with severe cerebral palsy across International Classification of Functioning, Disability and Health for Children and Youth version domains: a systematic review. Dev Med Child Neurol. 2015;57(10):919-30.

27. Humphreys G, King T, Jex J, Rogers M, Blake S, ThompsonCoon J, et al. Sleep positioning systems for children and adults with a neurodisability: a systematic review. London, England: SAGE Publications; 2019. p. 5-14.

28. Blake SF, Logan S, Humphreys G, Matthews J, Rogers M, Thompson-Coon J, et al. Sleep positioning systems for children with cerebral palsy. The Cochrane database of systematic reviews. 2015(11):Cd009257.

29. Galland BC, Elder DE, Taylor BJ. Interventions with a sleep outcome for children with cerebral palsy or a post-traumatic brain injury: a systematic review. Sleep Med Rev. 2012;16(6):561-73.

30. Chen Y-P, Howard AM. Effects of robotic therapy on upperextremity function in children with cerebral palsy: a systematic review. Dev Neurorehabil. 2016;19(1):64-71.

31. Cruz MA, Rios Rincon AM, Rodriguez Duenas WR, Quiroga Torres DA, Bohorquez-Heredia AF. What does the literature say about using robots on children with disabilities? Disabil Rehab Assistive Technol. 2017;12(5):429-40.

32. Zhang M, Davies TC, Xie S. Effectiveness of robot-assisted therapy on ankle rehabilitation-a systematic review. J Neuroeng Rehabil. 2013;10:30.

33. Chen Y, Fanchiang HD, Howard A. Effectiveness of virtual reality in children with cerebral palsy: a systematic review and metaanalysis of randomized controlled trials. Phys Ther. 2018;98(1): 63-77.

34. Lopes S, Magalhaes P, Pereira A, Martins J, Magalhaes C, Chaleta E, et al. Games used with serious purposes: a systematic review of interventions in patients with cerebral palsy. Front Psychol. 2018;9:1712.

35. Rathinam C, Mohan V, Peirson J, Skinner J, Nethaji KS, Kuhn I. Effectiveness of virtual reality in the treatment of hand function in children with cerebral palsy: a systematic review. J Hand Ther : Off J Am Soc Hand Ther. 2018.

36. Holtz BE, Murray K, Park T. Serious games for children with chronic diseases: a systematic review. Games Health J. 2018;7(5):291-301.

37. Hickman R, Popescu L, Manzanares R, Morris B, Lee SP, Dufek JS. Use of active video gaming in children with neuromotor dysfunction: a systematic review. Dev Med Child Neurol. 2017;59(9): 903-11.

38. Page ZE, Barrington S, Edwards J, Barnett LM. Do active video games benefit the motor skill development of non-typically developing children and adolescents: a systematic review. J Sci Med Sport. 2017;20(12):1087-100.

39. Ravi DK, Kumar N, Singhi P. Effectiveness of virtual reality rehabilitation for children and adolescents with cerebral palsy: an updated evidence-based systematic review. Physiotherapy. 2017;103(3):245-58.

40. Chiu HC, Kuo PW. Effects of virtual reality in children with cerebral palsy: a systematic review. FJPT. 2015;40(3):136-44.

41. Staiano AE, Flynn R. Therapeutic uses of active videogames: a systematic review. Games for Health. 2014;3(6):351-65.

42. Weiss PL, Tirosh E, Fehlings D. Role of virtual reality for cerebral palsy management. J Child Neurol. 2014;29(8):1119-24.

43. Chen YP, Lee SY, Howard AM. Effect of virtual reality on upper extremity function in children with cerebral palsy: a meta-analysis. 
PediatricPhys Ther : Off Publ Section Pediatric Am Phys Ther Assoc. 2014;26(3):289-300.

44. Bonnechere B, Jansen B, Omelina L, Degelaen M, Wermenbol V, Rooze M, et al. Can serious games be incorporated with conventional treatment of children with cerebral palsy? A review. Res Dev Disabil. 2014;35(8):1899-913.

45. Tatla SK, Sauve K, Jarus T, Virji-Babul N, Holsti L. The effects of motivating interventions on rehabilitation outcomes in children and youth with acquired brain injuries: a systematic review. Brain Inj. 2014;28(8):1022-35.

46. Inguaggiato E, Sgandurra G, Perazza S, Guzzetta A, Cioni G. Brain reorganization following intervention in children with congenital hemiplegia: a systematic review. Neural Plasticity. 2013;2013:356275.

47. Tatla SK, Sauve K, Virji-Babul N, Holsti L, Butler C, Van Der Loos HFM. Evidence for outcomes of motivational rehabilitation interventions for children and adolescents with cerebral palsy: an American Academy for Cerebral Palsy and Developmental Medicine systematic review. Dev Med Child Neurol. 2013;55(7): 593-601.

48. Yoo JW, Lee DR, Cha YJ, You SH. Augmented effects of EMG biofeedback interfaced with virtual reality on neuromuscular control and movement coordination during reaching in children with cerebral palsy. NeuroRehabilitation. 2017;40(2):175-85.

49. Cooper T, Williams JM. Does an exercise programme integrating the Nintendo Wii-Fit Balance Board improve balance in ambulatory children with cerebral palsy? Phys Ther Rev. 2017;22(5/6): 229-37.

50. Deutsch JE, Guarrera-Bowlby P, Myslinski MJ, Kafri M. Is there evidence that active videogames increase energy expenditure and exercise intensity for people poststroke and with cerebral palsy? Games for Health. 2015;4(1):31-7.

51. Therrien MCS, Light J, Pope L. Systematic review of the effects of interventions to promote peer interactions for children who use aided AAC2016.

52. Karlsson P, Allsop A, Dee-Price BJ, Wallen M. Eye-gaze control technology for children, adolescents and adults with cerebral palsy with significant physical disability: findings from a systematic review. Dev Neurorehabilitation. 2018;21(8):497-505.

53. McInerney MS, Reddihough DS, Carding PN, Swanton R, Walton $\mathrm{CM}$, Imms C. Behavioural interventions to treat drooling in children with neurodisability: a systematic review. Dev Med Child Neurol. 2019;61(1):39-48

54. Ferre CL, Brandao M, Surana B, Dew AP, Moreau NG, Gordon AM. Caregiver-directed home-based intensive bimanual training in young children with unilateral spastic cerebral palsy: a randomized trial. Dev Med Child Neurol. 2017;59(5):497-504.

55. Brandao MB, Mancini MC, Ferre CL, Figueiredo PRP, Oliveira RHS, Goncalves SC, et al. Does dosage matter? A pilot study of hand-arm bimanual intensive training (HABIT) dose and dosing schedule in children with unilateral cerebral palsy. Phys Occup Ther Pediatric. 2018;38(3):227-42.

56. Friel KM, Kuo H-C, Fuller J, Ferre CL, Brandao M, Carmel JB, et al. Skilled bimanual training drives motor cortex plasticity in children with unilateral cerebral palsy. Neurorehabil Neural Repair. 2016;30(9):834-44.

57. van Gelder L, Booth ATC, van de Port I, Buizer AI, Harlaar J, van der Krogt MM. Real-time feedback to improve gait in children with cerebral palsy. Gait Posture. 2017;52:76-82.

58. Rattanatharn R. Effect of EMG biofeedback to improve upper extremity in children with cerebral palsy: a randomized controlled trail. Chula Med. 2017;61(4):451-63.

59. Abdel-Rahman R, El-Gendy A. Impact of computer feedback on hand performance in cerebral palsied children. Indian J Physiother Occup Ther. 2014;8(3):214-9.
60. Tustin K, Patel A. A critical evaluation of the updated evidence for casting for equinus deformity in children with cerebral palsy. Physiotherapy Research International. 2017;22(1):n/a-N.PAG.

61. Novak I. Evidence to practice commentary new evidence in coaching interventions. Phys Occup Ther Pediatric. 2014;34(2): 132-7.

62. Hoare BJ, Wallen MA, Thorley MN, Jackman ML, Carey LM, Imms C. Constraint-induced movement therapy in children with unilateral cerebral palsy. The Cochrane database of systematic reviews. 2019:4:Cd004149.

63. Sakzewski L, Ziviani J, Boyd RN. Efficacy of upper limb therapies for unilateral cerebral palsy: a meta-analysis. Pediatrics. 2014;133(1):e175-204.

64. Chen YP, Pope S, Tyler D, Warren GL. Effectiveness of constraint-induced movement therapy on upper-extremity function in children with cerebral palsy: a systematic review and meta-analysis of randomized controlled trials. Clin Rehabil. 2014;28(10):939-53.

65. Das S, Ganesh G. Evidence-based approach to physical therapy in cerebral palsy. Indian J Orthop. 2019;53(1):20-34.

66. Jamali AR, Amini M. The effects of constraint induced movement therapy on functions of children with cerebral palsy. Iran J Child Neurol. 2018;12(4):16-27.

67. Fonseca PRJ, Filoni E, Melo Setter C, Marques Berbel A, Olival Fernandes A, Calhes de Franco Moura R. Constraint-induced movement therapy of upper limb of children with cerebral palsy in clinical practice: systematic review of the literature. Fisioterapia e Pesquisa. 2017;24(3):334-46.

68. Chiu H-C, Ada L. Constraint-induced movement therapy improves upper limb activity and participation in hemiplegic cerebral palsy: a systematic review. J Physiother(Elsevier). 2016;62(3): 130-7.

69. Adair B, Ullenhag A, Keen D, Granlund M, Imms C. The effect of interventions aimed at improving participation outcomes for children with disabilities: a systematic review. 2015. p. 1093-104.

70. Dong VA-Q, Tung IH-H, Siu HW-Y, Fong KN-K. Studies comparing the efficacy of constraint-induced movement therapy and bimanual training in children with unilateral cerebral palsy: a systematic review. Dev Neurorehabilitation. 2013;16(2):133-43.

71. Klepper SE, Clayton Krasinski D, Gilb MC, Khalil N. Comparing unimanual and bimanual training in upper extremity function in children with unilateral cerebral palsy. Pediatric Phys Ther : Off Publ Sect Pediatric Am Phys Ther Assoc. 2017;29(4):288-306.

72. Tervahauta MH, Girolami GL, Øberg GK. Efficacy of constraintinduced movement therapy compared with bimanual intensive training in children with unilateral cerebral palsy: a systematic review. Clin Rehabil. 2017;31(11):1445-56.

73. Jackman M, Novak I, Lannin N, Froude E, Miller L, Galea C. Effectiveness of cognitive orientation to daily occupational performance over and above functional hand splints for children with cerebral palsy or brain injury: a randomized controlled trial. BMC Pediatr. 2018;18(1):248.

74. Cameron D, Craig T, Edwards B, Missiuna C, Schwellnus H, Polatajko HJ. Cognitive orientation to daily occupational performance (CO-OP): a new approach for children with cerebral palsy. Phys Occup Ther Pediatric. 2017;37(2):183-98.

75. Gimeno GH, Brown JR, Lin JJ-P, Cornelius JV, Polatajko JH. Cognitive approach to rehabilitation in children with hyperkinetic movement disorders post-DBS. Neurology. 2019;92(11):e1212e24.

76. Peny-Dahlstrand M, Bergqvist L, Hofgren C, Himmelmann K, Ohrvall AM. Potential benefits of the cognitive orientation to daily occupational performance approach in young adults with spina bifida or cerebral palsy: a feasibility study. Disabil Rehabil. 2018:1-12. 
77. Kruijsen-Terpstra AJ, Ketelaar M, Verschuren O, Gorter JW, Vos $\mathrm{RC}$, Verheijden J, et al. Efficacy of three therapy approaches in preschool children with cerebral palsy: a randomized controlled trial. Dev Med Child Neurol. 2015;58(7):758-66.

78. Mlinda SJ, Leyna GH, Massawe A. The effect of a practical nutrition education programme on feeding skills of caregivers of children with cerebral palsy at Muhimbili National Hospital, in Tanzania. Child Care Health Dev. 2018;44(3):452-61.

79. Morgan C, Darrah J, Gordon AM, Harbourne R, Spittle A, Johnson R, et al. Effectiveness of motor interventions in infants with cerebral palsy: a systematic review. Dev Med Child Neurol. 2016;58(9):900-9.

80. Hadders-Algra M, Boxum AG, Hielkema T, Hamer EG. Effect of early intervention in infants at very high risk of cerebral palsy: a systematic review. Dev Med Child Neurol. 2017;59(3):246-58.

81. Case-Smith J, Frolek Clark GJ, Schlabach TL. Systematic review of interventions used in occupational therapy to promote motor performance for children ages birth-5 years. Am J Occup Ther: Off Publ Am Occup Ther Assoc. 2013;67(4):413-24.

82. Holmstrom L, Eliasson AC, Almeida R, Furmark C, Weiland AL, Tedroff $\mathrm{K}$, et al. Efficacy of the small step program in a randomized controlled trial for infants under 12 months old at risk of cerebral palsy (CP) and other neurological disorders. Journal of clinical medicine. 2019;8(7).

83. Morgan C, Novak I, Dale RC, Badawi N. Optimising motor learning in infants at high risk of cerebral palsy: a pilot study. (Clinical report). BMC pediatrics. 2015;15(1).

84. Morgan C, Novak I, Dale RC, Guzzetta A, Badawi N. Single blind randomised controlled trial of GAME (goals-activity-motor enrichment) in infants at high risk of cerebral palsy. Res Dev Disabil. 2016;55:256-67.

85. Eliasson A-C, Nordstrand L, Ek L, Lennartsson F, Sjostrand L, Tedroff K, et al. The effectiveness of baby-CIMT in infants younger than 12 months with clinical signs of unilateral-cerebral palsy; an explorative study with randomized design. Res Dev Disabil. 2018;72:191-201.

86. Chamudot R, Parush S, Rigbi A, Horovitz R, Gross-Tsur V. Effectiveness of modified constraint-induced movement therapy compared with bimanual therapy home programs for infants with hemiplegia: a randomized controlled trial. Am J Occup Ther : Off Publ Am Occup Ther Assoc. 2018;72(6):7206205010p1-p9.

87. Hielkema T, Hamer EG, Boxum AG, La Bastide-Van Gemert S, Dirks T, Reinders-Messelink HA, et al. LEARN2MOVE 0-2 years, a randomized early intervention trial for infants at very high risk of cerebral palsy: neuromotor, cognitive, and behavioral outcome. Disabil Rehabil. 2019:1-10.

88. Hielkema T, Boxum AG, Hamer EG, La Bastide-Van Gemert S, Dirks T, Reinders-Messelink HA, et al. LEARN2MOVE 0-2 years, a randomized early intervention trial for infants at very high risk of cerebral palsy: family outcome and infant's functional outcome. Disabil Rehabil. 2019:1-9.

89. Blauw-Hospers CH, Dirks T, Hulshof LJ, Bos AF, Hadders-Algra M. Pediatric physical therapy in infancy: from nightmare to dream? A two-arm randomized trial. Phys Ther. 2011;91(9): 1323-38.

90. Hielkema T, Blauw-Hospers CH, Dirks T, Drijver-Messelink M, Bos AF, Hadders-Algra M. Does physiotherapeutic intervention affect motor outcome in high-risk infants? An approach combining a randomized controlled trial and process evaluation. Dev Med Child Neurol. 2011;53(3):e8-15.

91. Ziviani J, Feeney R, Rodger S, Watter P. Systematic review of early intervention programmes for children from birth to nine years who have a physical disability. Aust Occup Ther J. 2010;57(4):210-23.

92. Chiu HC, Ada L. Effect of functional electrical stimulation on activity in children with cerebral palsy: a systematic review.
Pediatric Phys Ther : Off Publ Sect Pediatric Am Phys Ther Assoc. 2014;26(3):283-8.

93. Moll I, Vles JSH, Soudant DLHM, Witlox AMA, Staal HM, Speth LAWM, et al. Functional electrical stimulation of the ankle dorsiflexors during walking in spastic cerebral palsy: a systematic review. Dev Med Child Neurol. 2017;59(12):1230-6.

94. Salazar AP, Pagnussat AS, Pereira GA, Scopel G, Lukrafka JL. Neuromuscular electrical stimulation to improve gross motor function in children with cerebral palsy: a meta-analysis. Brazilian Journal of Physical Therapy 2019.

95. Morgan C, Novak I, Badawi N. Enriched environments and motor outcomes in cerebral palsy: systematic review and meta-analysis. Pediatrics. 2013;132(3):e735-46.

96. Ryan JM, Cassidy EE, Noorduyn SG, O'Connell NE. Exercise interventions for cerebral palsy. Cochrane Database Syst Rev 2017(6).

97. Ritzmann R, Stark C, Krause A. Vibration therapy in patients with cerebral palsy: a systematic review. Neuropsychiatr Dis Treat Vol 14 2018, ArtID 1607-1625. 2018;14.

98. Toovey R, Bernie C, Harvey AR, McGinley JL, Spittle AJ. Taskspecific gross motor skills training for ambulant school-aged children with cerebral palsy: a systematic review. BMJ paediatrics open. 2017;1(1):e000078.

99. Bleyenheuft Y, Arnould C, Brandao MB, Bleyenheuft C, Gordon AM. Hand and arm bimanual intensive therapy including lower extremity (HABIT-ILE) in children with unilateral spastic cerebral palsy: a randomized trial. Neurorehabil Neural Repair. 2015;29(7):645-57.

100. Bleyenheuft Y, Ebner-Karestinos D, Surana B, Paradis J, Sidiropoulos A, Renders A, et al. Intensive upper- and lowerextremity training for children with bilateral cerebral palsy: a quasi-randomized trial. Dev Med Child Neurol. 2017;59(6): 625-33.

101. Plasschaert VFP, Vriezekolk JE, Aarts PBM, Geurts ACH, Van den Ende CHM. Interventions to improve upper limb function for children with bilateral cerebral palsy: a systematic review. Dev Med Child Neurol. 2019.

102. Charry-Sanchez JD, Pradilla I, Talero-Gutierrez C. Effectiveness of animal-assisted therapy in the pediatric population: systematic review and meta-analysis of controlled studies. J Dev Behav Pediatric: JDBP. 2018;39(7):580-90.

103. Tseng SH, Chen HC, Tam KW. Systematic review and metaanalysis of the effect of equine assisted activities and therapies on gross motor outcome in children with cerebral palsy. Disabil Rehabil. 2013;35(2):89-99.

104. MacKinnon JR, Noh S, Lariviere J, MacPhail A, Allan DE, Laliberte D. A study of therapeutic effects of horseback riding for children with cerebral palsy. Phys Occup Ther Pediatric. 1995;15(1):17-34.

105. Kwon J-Y, Chang HJ, Lee JY, Ha Y, Lee PK, Kim Y-H. Effects of hippotherapy on gait parameters in children with bilateral spastic cerebral palsy. Arch Phys Med Rehabil. 2011;92(5):774-9.

106. Kwon J-Y, Chang HJ, Yi S-H, Lee JY, Shin H-Y, Kim Y-H. Effect of hippotherapy on gross motor function in children with cerebral palsy: a randomized controlled trial. J Altern Complement Med. 2015;21(1):15-21.

107. Matusiak-Wieczorek E, Małachowska-Sobieska M, Synder M. Influence of hippotherapy on body balance in the sitting position among children with cerebral palsy. Ortopedia, Traumatologia, Rehabilitacja. 2016;18(2):165-75.

108. Dewar R, Love S, Johnston LM. Exercise interventions improve postural control in children with cerebral palsy: a systematic review. Dev Med Child Neurol. 2015;57(6):504-20.

109. Lucena-Antón D, Rosety-Rodriguez I, Moral-Munoz JA. Effects of a hippotherapy intervention on muscle spasticity in children 
with cerebral palsy: a randomized controlled trial. Complement Ther Clin Pract. 2018;31:188-92.

110. Lee CW, Kim SG, Na SS. The effects of hippotherapy and a horse riding simulator on the balance of children with cerebral palsy. $\mathrm{J}$ Phys Ther Sci. 2014;26(3):423-5.

111. Temcharoensuk P, Lekskulchai R, Akamanon C, Ritruechai P, Sutcharitpongsa S. Effect of horseback riding versus a dynamic and static horse riding simulator on sitting ability of children with cerebral palsy: a randomized controlled trial. J Phys Ther Sci. 2015;27(1):273-7.

112. Novak I, Berry J. Home program intervention effectiveness evidence. Phys Occup Ther Pediatric. 2014;34(4):384-9.

113. Roostaei M, Baharlouei H, Azadi H, Fragala-Pinkham MA. Effects of aquatic intervention on gross motor skills in children with cerebral palsy: a systematic review. Phys Occup Ther Pediatric. 2017;37(5):496-515.

114. Pennington L, Akor WA, Laws K, Goldbart J. Parent-mediated communication interventions for improving the communication skills of preschool children with non-progressive motor disorders. The Cochrane database of systematic reviews. 2018;7:Cd012507.

115. Chorna O, Hamm E, Cummings C, Fetters A, Maitre NL. Speech and language interventions for infants aged 0 to 2 years at high risk for cerebral palsy: a systematic review. Dev Med Child Neurol. 2016;59(4):355-60.

116. Pennington L, Goldbart J, Marshall J. Speech and language therapy to improve the communication skills of children with cerebral palsy. Cochrane Database Syst Rev. 2016;3.

117. Mandak K, Light J, Boyle S. The effects of literacy interventions on single-word reading for individuals who use aided AAC: a systematic review. AAC: Augmentative \& Alternative Communication. 2018;34(3):206-18.

118. Barker MR, Saunders KJ, Brady NC. Reading instruction for children who use AAC: considerations in the pursuit of generalizable results 2012.

119. Stauter DW, Myers SR, Classen AI. Literacy instruction for young children with severe speech and physical impairments: a systematic review 2017

120. Park EJ, Baek SH, Park S. Systematic review of the effects of mirror therapy in children with cerebral palsy. J Phys Ther Sci. 2016;28(11):3227-31.

121. Auld ML, Johnston LM, Russo RN, Moseley GL. A single session of mirror-based tactile and motor training improves tactile dysfunction in children with unilateral cerebral palsy: a replicated randomized controlled case series. Physiotherapy Research International. 2017;22(4):n/a-n/a.

122. Bania T, Chiu HC, Billis E. Activity training on the ground in children with cerebral palsy: systematic review and meta-analysis. Physiother Theory Pract. 2018:1-12.

123. Booth ATC, Buizer AI, Meyns P, Oude Lansink ILB, Steenbrink F, van der Krogt MM. The efficacy of functional gait training in children and young adults with cerebral palsy: a systematic review and meta-analysis. Dev Med Child Neurol. 2018;60(9):866-83.

124. Clutterbuck G, Auld M, Johnston L. Active exercise interventions improve gross motor function of ambulant/semi-ambulant children with cerebral palsy: a systematic review. Disabil Rehabil. 2018:1-21

125. Elnahhas AM, Elshennawy S, Aly MG. Effects of backward gait training on balance, gross motor function, and gait in children with cerebral palsy: a systematic review. Clin Rehabil. 2019;33(1):3-12.

126. Paleg G, Livingstone R. Outcomes of gait trainer use in home and school settings for children with motor impairments: a systematic review. Clin Rehabil. 2015;29(11):1077-91.

127. Moreau NG, Winter Bodkin A, Bjornson K, Hobbs A, Soileau M, Lahasky K. Effectiveness of rehabilitation interventions to improve gait speed in children with cerebral palsy: systematic review and meta-analysis. Phys Ther. 2016;96(12):1938-54.
128. Chappell A, Gibson N, Morris S, Williams G, Allison GT. Running in people with cerebral palsy: a systematic review. Physiother Theory Pract. 2019;35(1):15-30.

129. Zanon MA, Pacheco RL, Latorraca COC, Martimbianco ALC, Pachito DV, Riera R. Neurodevelopmental treatment (Bobath) for children with cerebral palsy: a systematic review. J Child Neurol 2019:883073819852237.

130. Labaf S, Shamsoddini A, Hollisaz MT, Sobhani V, Shakibaee A. Effects of neurodevelopmental therapy on gross motor function in children with cerebral palsy. Iran J Child Neurol. 2015;9(2):36-41.

131. Batra M, Sharma VP, Batra V, Malik GK, Pandey RM. Neurofacilitation of developmental reaction (NFDR) approach: a practice framework for integration / modification of early motor behavior (primitive reflexes) in cerebral palsy. Indian J Pediatr. 2012;79(5):659-63.

132. Ari G, Gunel MK. A randomised controlled study to investigate effects of Bobath based trunk control training on motor function of children with spastic bilateral cerebral palsy. Int J Clin Med. 2017;8:205-15.

133. Morgan AT, Dodrill P, Ward EC. Interventions for oropharyngeal dysphagia in children with neurological impairment. Cochrane Database Syst Rev 2012(10).

134. Arvedson J, Clark H, Lazarus C, Schooling T, Frymark T. The effects of oral-motor exercises on swallowing in children: an evidence-based systematic review. Dev Med Child Neurol. 2010;52(11):1000-13.

135. Sigan SN, Uzunhan TA, Aydinli N, Eraslan E, Ekici B, Caliskan M. Effects of oral motor therapy in children with cerebral palsy. Ann Indian Acad Neurol. 2013;16(3):342-6.

136. Khamis A, Novak I, Morgan C, Tzannes G, Pettigrew J, Cowell J, et al. Motor learning feeding interventions for infants at risk of cerebral palsy: a systematic review. Dysphagia. 2019.

137. Inal Ö, Serel Arslan S, Demir N, Tunca Yilmaz Ö, Karaduman AA. Effect of functional chewing training on tongue thrust and drooling in children with cerebral palsy: a randomised controlled trial. J Oral Rehabil. 2017;44(11):843-9.

138. Umay E, Gurcay E, Ozturk EA, Unlu AE. Is sensory-level electrical stimulation effective in cerebral palsy children with dysphagia? A randomized controlled clinical trial. Acta Neurol Belg. 2019.

139. Song WJ, Park JH, Lee JH, Kim MY. Effects of neuromuscular electrical stimulation on swallowing functions in children with cerebral palsy: a pilot randomised controlled trial. Hong Kong J Occup Ther. 2015;25(1):1-6.

140. Jackman M, Novak I, Lannin N. Effectiveness of hand splints in children with cerebral palsy: a systematic review with meta-analysis. Dev Med Child Neurol. 2013;56(2):138-47.

141. Garbellini S, Robert Y, Randall M, Elliott C, Imms C. Rationale for prescription, and effectiveness of, upper limb orthotic intervention for children with cerebral palsy: a systematic review. Disabil Rehabil. 2018;40(12):1361-71.

142. Reedman S, Boyd RN, Sakzewski L. The efficacy of interventions to increase physical activity participation of children with cerebral palsy: a systematic review and meta-analysis. Dev Med Child Neurol. 2017;59(10):1011-8.

143. Bloemen M, Van Wely L, Mollema J, Dallmeijer A, de Groot J. Evidence for increasing physical activity in children with physical disabilities: a systematic review. Dev Med Child Neurol. 2017;59(10):1004-10.

144. O’Brien TD, Noyes J, Spencer LH, Kubis HP, Hastings RP, Whitaker R. Systematic review of physical activity and exercise interventions to improve health, fitness and well-being of children and young people who use wheelchairs. BMJ Open Sport Exerc Med. 2016;2(1):e000109. 
145. Hsieh HC. Effectiveness of adaptive pretend play on affective expression and imagination of children with cerebral palsy. Res Dev Disabil. 2012;33(6):1975-83.

146. Gmelig Meyling C, Ketelaar M, Kuijper MA, Voorman J, Buizer AI. Effects of postural management on hip migration in children with cerebral palsy: a systematic review. Pediatric Phys Ther: Off Publ Section Pediatric Am Physi Ther Assoc. 2018;30(2):82-91.

147. Miller S, Juricic M, Hesketh K, McLean L, Magnuson S, Gasior S, et al. Prevention of hip displacement in children with cerebral palsy: a systematic review. Dev Med Child Neurol. 2017;58(Supplement 5):62-3.

148. McLean B, Taylor S, Blair E, Valentine J, Carey L, Elliott C. Somatosensory discrimination intervention improves body position sense and motor performance in children with hemiplegic cerebral palsy. AJOT: American Journal of Occupational Therapy. 2017;71(3).

149. Auld ML, Russo R, Moseley GL, Johnston LM. Determination of interventions for upper extremity tactile impairment in children with cerebral palsy: a systematic review. Dev Med Child Neurol. 2014;56(9):815-32.

150. Rigney G, Ali NS, Corkum PV, Brown CA, Constantin E, Godbout R, et al. A systematic review to explore the feasibility of a behavioural sleep intervention for insomnia in children with neurodevelopmental disorders: a transdiagnostic approach. Sleep Med Rev. 2018;41:244-54.

151. Park EY, Kim WH. Meta-analysis of the effect of strengthening interventions in individuals with cerebral palsy. Res Dev Disabil. 2013;35(2):239-49.

152. Abbaskhanian A, Rashedi V, Delpak A, Vameghi R, Gharib M. Rehabilitation interventions for children with cerebral palsy: a systematic review. J Pediatric Rev. 2015:1-8.

153. Rameckers EAA, Janssen-Potten YJM, Essers IMM, Smeets RJEM. Efficacy of upper limb strengthening in children with cerebral palsy: a critical review. Res Dev Disabil. 2014;36:87-101.

154. Gillett JG, Boyd RN, Carty CP, Barber LA. The impact of strength training on skeletal muscle morphology and architecture in children and adolescents with spastic cerebral palsy: a systematic review. Res Dev Disabil. 2016;56:183-96.

155. Eldridge F, Lavin N. How effective is stretching in maintaining range of movement for children with cerebral palsy? A critical review. Int J Ther Rehabil. 2016;23(8):386-95.

156. Wells H, Marquez J, Wakely L. Garment therapy does not improve function in children with cerebral palsy: a systematic review. Phys Occup Ther Pediatric. 2018;38(4):395-416.

157. Martins E, Cordovil R, Oliveira R, Letras S, Lourenco S, Pereira I, et al. Efficacy of suit therapy on functioning in children and adolescents with cerebral palsy: a systematic review and meta-analysis. Dev Med Child Neurol. 2015;58(4):348-60.

158. Almeida KM, Fonseca ST, Figueiredo PRP, Aquino AA, Mancini MC. Effects of interventions with therapeutic suits (clothing) on impairments and functional limitations of children with cerebral palsy: a systematic review. Braz J Phys Ther / Rev Bras Fisioterapia. 2017;21(5):307-20.

159. Unger M, Carstens JP, Fernandes N, Pretorius R, Pronk S, Robinson AC, et al. The efficacy of kinesiology taping for improving gross motor function in children with cerebral palsy: a systematic review. South African Journal of Physiotherapy. 2018;74(1):N.PAG-N.PAG.

160. Cunha AB, Lima-Alvarez CD, Rocha ACP, Tudella E. Effects of elastic therapeutic taping on motor function in children with motor impairments: a systematic review. Disabil Rehabil. 2018;40(14): 1609-17.

161. Fonseca PR Jr, Calhes Franco de Moura R, Galli M, Santos Oliveira C. Effect of physiotherapeutic intervention on the gait after the application of botulinum toxin in children with cerebral palsy: systematic review. Eur J Phys Rehabil Med. 2018;54(5): 757-65.

162. Guchan Z, Mutlu A. The effectiveness of taping on children with cerebral palsy: a systematic review. Dev Med Child Neurol. 2016;59(1):26-30.

163. Shamsoddini A, Rasti Z, Kalantari M, Hollisaz MT, Sobhani V, Dalvand $\mathrm{H}$, et al. The impact of Kinesio taping technique on children with cerebral palsy. Iran J Neurol. 2016;15(4):219-27.

164. de Sousa RRJ, de Lima P, Neves da Silva J, Vaz DV. Effects of kinesiology taping in children with cerebral palsy: a systematic review. Fisioterapia em Movimento. 2017;30:S373-S82.

165. Ortiz Ramirez J, Perez de la Cruz S. Therapeutic effects of Kinesio taping in children with cerebral palsy: a systematic review. Arch Argent Pediatr 2017;115(6):e356-ee61.

166. Saleem GT, Crasta JE, Slomine BS, Cantarero GL, Suskauer SJ. Transcranial direct current stimulation in pediatric motor disorders: a systematic review and meta-analysis. Arch Phys Med Rehabil. 2019;100(4):724-38.

167. Krishnan C, Santos L, Peterson MD, Ehinger M. Safety of noninvasive brain stimulation in children and adolescents. Brain Stimulation. 2015;8(1):76-87.

168. Hamilton A, Wakely L, Marquez J. Transcranial direct-current stimulation on motor function in pediatric cerebral palsy: a systematic review. Pediatr Phys Ther. 2018;30(4):291-302.

169. Lefmann S, Russo R, Hillier S. The effectiveness of roboticassisted gait training for paediatric gait disorders: systematic review. J Neuroeng Rehabil. 2017;14(1):1.

170. Tramontano M, Medici A, Iosa M, Chiariotti A, Fusillo G, Manzari L, et al. The effect of vestibular stimulation on motor functions of children with cerebral palsy. Mot Control. 2017;21(3):299-311.

171. Kim SJ, Kim SN, Yang YN, Lee IS, Koh SE. Effect of weight bearing exercise to improve bone mineral density in children with cerebral palsy: a meta-analysis. J Musculoskelet Neuronal Interact. 2017;17(4):334-40.

172. Saquetto M, Carvalho V, Silva C, Conceicao C, Gomes-Neto M. The effects of whole body vibration on mobility and balance in children with cerebral palsy: a systematic review with meta-analysis. J Musculoskelet Neuronal Interact. 2015;15(2):137-44.

173. Duquette SA, Guiliano AM, Starmer DJ. Whole body vibration and cerebral palsy: a systematic review. J Canad Chiropractic Assoc. 2015;59(3):245-52.

174. Sa-Caputo DC, Costa-Cavalcanti R, Carvalho-Lima RP, Arnobio A, Bernardo RM, Ronikeile-Costa P, et al. Systematic review of whole body vibration exercises in the treatment of cerebral palsy: brief report. Dev Neurorehabil. 2016;19(5):327-33.

175. Buizer AI, Martens BHM, Grandbois van Ravenhorst C, Schoonmade LJ, Becher JG, Vermeulen RJ. Effect of continuous intrathecal baclofen therapy in children: a systematic review. Dev Med Child Neurol. 2019;61(2):128-34.

176. Hasnat MJ, Rice JE. Intrathecal baclofen for treating spasticity in children with cerebral palsy. Cochrane Database Syst Rev. 2015;11.

177. Fehlings D, Brown L, Harvey A, Himmelmann K, Lin JP, Macintosh A, et al. Pharmacological and neurosurgical interventions for managing dystonia in cerebral palsy: a systematic review. Dev Med Child Neurol. 2018;60(4):356-66.

178. Tsoi WS, Zhang LA, Wang WY, Tsang KL, Lo SK. Improving quality of life of children with cerebral palsy: a systematic review of clinical trials. Child Care Health Dev. 2012;38(1):21-31.

179. Ostojic K, Paget S, Burton K, Morrow A. The management of pain in children and adolescents with cerebral palsy: a systematic literature review. Dev Med Child Neurol. 2018;60(Supplement 1): 29.

180. Beecham E, Candy B, Howard R, McCulloch R, Laddie J, Rees H, et al. Pharmacological interventions for pain in children and 
adolescents with life-limiting conditions. The Cochrane database of systematic reviews. 2015(3):Cd010750.

181. Navarrete-Opazo AA, Gonzalez W, Nahuelhual P. Effectiveness of oral baclofen in the treatment of spasticity in children and adolescents with cerebral palsy. Arch Phys Med Rehabil. 2016;97(4): $604-18$

182. Ward R, Reynolds JE, Bear N, Elliott C, Valentine J. What is the evidence for managing tone in young children with, or at risk of developing, cerebral palsy: a systematic review. Disabil Rehabil. 2017;39(7):619-30.

183. Kim MJ, Kim SN, Lee IS, Chung S, Lee J, Yang Y, et al. Effects of bisphosphonates to treat osteoporosis in children with cerebral palsy: a meta-analysis. J Pediatric Endocrinol Metab: JPEM. 2015;28(11-12):1343-50.

184. Ozel S, Switzer L, Macintosh A, Fehlings D. Informing evidencebased clinical practice guidelines for children with cerebral palsy at risk of osteoporosis: an update. Dev Med Child Neurol. 2016;58(9):918-23.

185. Kahraman A, Seyhan K, Değer Ü, Kutlutürk S, Mutlu A. Should botulinum toxin A injections be repeated in children with cerebral palsy? A systematic review. Dev Med Child Neurol. 2016;58(9): 910-7.

186. Druschel C, Althuizes HC, Funk JF, Placzek R. Off label use of botulinum toxin in children under two years of age: a systematic review. Toxins. 2013;5(1):60-72.

187. Pin TW, Elmasry J, Lewis J. Efficacy of botulinum toxin a in children with cerebral palsy in Gross Motor Function Classification System levels IV and V: a systematic review. Dev Med Child Neurol. 2013;55(4):304-13.

188. Sridharan K, Sivaramakrishnan G. Pharmacological interventions for treating sialorrhea associated with neurological disorders: a mixed treatment network meta-analysis of randomized controlled trials. J Clin Neurosci: Off J Neurosurg Soc Australasia. 2018;51: 12-7.

189. Rodwell K, Edwards P, Ware RS, Boyd R. Salivary gland botulinum toxin injections for drooling in children with cerebral palsy and neurodevelopmental disability: a systematic review. Dev Med Child Neurol. 2012;54(11):977-87.

190. Mathevon L, Bonan I, Barnais JL, Boyer F, Dinomais M. Adjunct therapies to improve outcomes after botulinum toxin injection in children: a systematic review. Annals of physical and rehabilitation medicine. 2018

191. Yana M, Tutuola F, Westwater-Wood S, Kavlak E. The efficacy of botulinum toxin a lower limb injections in addition to physiotherapy approaches in children with cerebral palsy: a systematic review. NeuroRehabilitation. 2019.

192. Dias BL, Fernandes AR, Maia Filho HS. Sialorrhea in children with cerebral palsy. J Pediatr. 2016;92(6):549-58.

193. Liow NY, Gimeno H, Lumsden DE, Marianczak J, Kaminska M, Tomlin S, et al. Gabapentin can significantly improve dystonia severity and quality of life in children. Eur J Paediatric Neurol: EJPN : Off J Eur Paediatric Neurol Soc. 2015;20(1):100-7.

194. Eiland LS. Glycopyrrolate for chronic drooling in children. Clin Ther. 2012;34(4):735-42.

195. Gonnade N, Lokhande V, Ajij M, Gaur A, Shukla K. Phenol versus botulinum toxin a injection in ambulatory cerebral palsy spastic diplegia: a comparative study. J Pediatr Neurosci. 2017;12(4):338-43.

196. Masson R, Pagliano E, Baranello G. Efficacy of oral pharmacological treatments in dyskinetic cerebral palsy: a systematic review. Dev Med Child Neurol. 2017;59(12):1237-48.

197. Harvey AR, Baker LB, Reddihough SD, Scheinberg A, Williams K. Trihexyphenidyl for dystonia in cerebral palsy. Cochrane Database Syst Rev. 2018;5.
198. Elia AE, Bagella CF, Ferre F, Zorzi G, Calandrella D, Romito LM. Deep brain stimulation for dystonia due to cerebral palsy: a review. Eur J Paediatr Neurol. 2018;22(2):308-15.

199. Dieguez-Perez M, de Nova-Garcia MJ, Mourelle-Martinez MR, Bartolome-Villar B. Oral health in children with physical (cerebral palsy) and intellectual (down syndrome) disabilities: systematic review I. J Clin Exp Dent. 2016;8(3):e337-43.

200. Carty CP, Walsh HPJ, Gillett JG, Phillips T, Edwards JM, de Lacy $\mathrm{M}$, et al. The effect of femoral derotation osteotomy on transverse plane hip and pelvic kinematics in children with cerebral palsy: a systematic review and meta-analysis. Gait Posture. 2014;40(3): 333-40.

201. Brun AC, Stordal K, Johannesdottir GB, Fossum V, Bentsen BS, Medhus AW. Nissen fundoplication in children with cerebral palsy: influence on rate of gastric emptying and postprandial symptoms in relation to protein source in caloric liquid meals. Clinical nutrition (Edinburgh, Scotland). 2013;32(4):619-23.

202. Islek A, Sayar E, Yilmaz A, Artan R. Percutaneous endoscopic gastrostomy in children: is early feeding safe? J Pediatr Gastroenterol Nutr. 2013;57(5):659-62.

203. Ferluga ED, Sathe NA, Krishnaswami S, McPheeters ML. Surgical intervention for feeding and nutrition difficulties in cerebral palsy: a systematic review. Dev Med Child Neurol. 2014;56(1):31-43.

204. Wynter M, Gibson N, Willoughby KL, Love S, Kentish M, Thomason P, et al. Australian hip surveillance guidelines for children with cerebral palsy: 5-year review. Dev Med Child Neurol. 2015;57(9):808-20.

205. El-Sobky TA, Fayyad TA, Kotb AM, Kaldas B. Bony reconstruction of hip in cerebral palsy children Gross Motor Function Classification System levels III to V: a systematic review. J Pediatric Orthop: Part B. 2018;27(3):221-30.

206. Hesketh K, Leveille L, Mulpuri K. The frequency of AVN following reconstructive hip surgery in children with cerebral palsy: a systematic review. J Pediatr Orthop. 2016;36(2):e17-24.

207. Kolman SE, Ruzbarsky JJ, Spiegel DA, Baldwin KD. Salvage options in the cerebral palsy hip: a systematic review. J Pediatr Orthop. 2016;36(6):645-50.

208. Boldingh EJ, Bouwhuis CB, van der Heijden-Maessen HCM, Bos CF, Lankhorst GJ. Palliative hip surgery in severe cerebral palsy: a systematic review. J Pediatric Orthop: Part B. 2014;23(1):86-92.

209. Ontario health technology assessment series: Lumbosacral dorsal rhizotomy for spastic cerebral palsy: a health technology assessment. 2017;17(10):1-186.

210. Toovey R, Harvey A, Johnson M, Baker L, Williams K. Outcomes after scoliosis surgery for children with cerebral palsy: a systematic review. Dev Med Child Neurol. 2017;59(7):690-8.

211. Legg J, Davies E, Raich AL, Dettori JR, Sherry N. Surgical correction of scoliosis in children with spastic quadriplegia: benefits, adverse effects, and patient selection. Evidence-Based Spine-care J. 2014;5(1):38-51.

212. Difazio LR, Miller EP, Vessey AJ, Snyder DB. Health-related quality of life and care giver burden following spinal fusion in children with cerebral palsy. SPINE. 2017;42(12):E733-E9.

213. Jain AA, Sullivan FB, Shah CS, Samdani DA, Yaszay DB, Marks $\mathrm{DM}$, et al. Caregiver perceptions and health-related quality-of-life changes in cerebral palsy patients after spinal arthrodesis. SPINE. 2018;43(15).

214. Miyanji AF, Nasto DL, Sponseller AP, Shah FS, Samdani HA, Lonner OB, et al. Assessing the risk-benefit ratio of scoliosis surgery in cerebral palsy: surgery is worth it. J Bone Joint Surg. 2018;100(7):556-63.

215. Miller DJ, Flynn JJM, Pasha S, Yaszay B, Parent S, Asghar J, et al. Improving health-related quality of life for patients with nonambulatory cerebral palsy: who stands to gain from scoliosis surgery? Journal of pediatric orthopedics. 2019. 
216. Amirmudin NA, Lavelle G, Theologis T, Thompson N, Ryan JM. Multilevel surgery for children with cerebral palsy: a meta-analysis. Pediatrics. 2019;143(4).

217. Lamberts RP, Burger M, du Toit J, Langerak NG. A systematic review of the effects of single-event multilevel surgery on gait parameters in children with spastic cerebral palsy. PLoS One. 2016;11(10):e0164686.

218. Firth GB, Passmore E, Sangeux M, Thomason P, Rodda J, Donath $\mathrm{S}$, et al. Multilevel surgery for equinus gait in children with spastic diplegic cerebral palsy: medium-term follow-up with gait analysis. J Bone Joint Surg Am. 2013;95(10):931-8.

219. Galey SA, Lerner ZF, Bulea TC, Zimbler S, Damiano DL. Effectiveness of surgical and non-surgical management of crouch gait in cerebral palsy: a systematic review. Gait Posture. 2017;54: 93-105.

220. Jung HJ, Yoon JY, Oh MK, Kim YC, Kim JH, Eom TW, et al. Effects of soft tissue surgery on pelvic and hip rotation in patients with spastic diplegia: a meta-analysis. Clin Orthop Surg. 2016;8(2):187-93.

221. Novak I, Walker K, Hunt RW, Wallace EM, Fahey M, Badawi N. Concise review: stem cell interventions for people with cerebral palsy: systematic review with meta-analysis. Stem Cells Transl Med. 2016;5(8):1014-25.

222. Kulak-Bejda A, Kulak P, Bejda G, Krajewska-Kulak E, Kulak W. Stem cells therapy in cerebral palsy: a systematic review. Brain Dev. 2016;38(8):699-705.

223. Huang L, Zhang C, Gu J, Wu W, Shen Z, Zhou X, et al. A randomized, placebo-controlled trial of human umbilical cord blood mesenchymal stem cell infusion for children with cerebral palsy. Cell Transplant. 2018;27(2):325-34.

224. Liu X, Fu X, Dai G, Wang X, Zhang Z, Cheng H, et al. Comparative analysis of curative effect of bone marrow mesenchymal stem cell and bone marrow mononuclear cell transplantation for spastic cerebral palsy. J Transl Med. 2017;15(1):48.

225. Rah WJ, Lee YH, Moon JH, Jun HJ, Kang HR, Koh H, et al. Neuroregenerative potential of intravenous G-CSF and autologous peripheral blood stem cells in children with cerebral palsy: a randomized, double-blind, cross-over study. J Transl Med. 2017;15(1):16

226. Park KI, Lee YH, Rah WJ, Jo SH, Park SB, Han SH, et al. Effect of intravenous infusion of G-CSF-mobilized peripheral blood mononuclear cells on upper extremity function in cerebral palsy children. Ann Rehabil Med. 2017;41(1):113-20.

227. Li LX, Zhang MM, Zhang Y, He J. Acupuncture for cerebral palsy: a meta-analysis of randomized controlled trials. Neural Regen Res. 2018;13(6):1107-17.

228. Mandziuk K, Liu Y, Adams D, Vohra S. Acupuncture for cerebral palsy. Focus Altern Complemen Ther. 2012;17(2):85-90.

229. Kwon CY, Lee B, Chang GT, Yoon SH. Efficacy of acupotomy for cerebral palsy: a systematic review and meta-analysis. Medicine. 2019;98(4):e14187.

230. Li LY, Liu ZH, Xie QL. Meta-analysis on scalp acupuncture based therapy in treating children cerebral palsy. World J Acupuncture Moxibustion. 2014;24(3):49-53.

231. Myrhaug HT, Odgaard-Jensen J, Ostensjo S, Vollestad NK, Jahnsen R. Effects of a conductive education course in young children with cerebral palsy: a randomized controlled trial. Dev Neurorehabil. 2018;21(8):481-9.

232. Myrhaug HT, Odgaard-Jensen J, Jahnsen R. The long-term effects of conductive education courses in young children with cerebral palsy: a randomized controlled trial. Dev Neurorehabil. 2019;22(2):111-9.

233. Lee B, Kwon CY, Chang GT. Oriental herbal medicine for neurological disorders in children: an overview of systematic reviews. Am J Chin Med. 2018;46(8):1701-26.
234. Novak I, Badawi N. "Hyperbaric oxygen treatment": reply. Ann Neurol. 2013;74(1):150-1.

235. Long Y, Tan J, Nie Y, Lu Y, Mei X, Tu C. Hyperbaric oxygen therapy is safe and effective for the treatment of sleep disorders in children with cerebral palsy. Neurol Res. 2017;39(3):239-47.

236. Rasool F, Memon AR, Kiyani MM, Sajjad AG. The effect of deep cross friction massage on spasticity of children with cerebral palsy: a double-blind randomised controlled trial. JPMA J Pakistan Med Assoc. 2017;67(1):87-91.

237. Orhan C, Kaya Kara O, Kaya S, Akbayrak T, Kerem Gunel M, Baltaci G. The effects of connective tissue manipulation and Kinesio taping on chronic constipation in children with cerebral palsy: a randomized controlled trial. Disabil Rehabil. 2018;40(1): $10-20$.

238. Silva LM, Schalock M, Garberg J, Smith CL. Qigong massage for motor skills in young children with cerebral palsy and down syndrome. Am J Occup Ther. 2012;66(3):348-55.

239. Cerritelli F, Ruffini N, Lacorte E, Vanacore N. Osteopathic manipulative treatment in neurological diseases: systematic review of the literature. J Neurol Sci. 2016;369:333-41.

240. Posadzki P, Lee MS, Ernst E. Osteopathic manipulative treatment for pediatric conditions: a systematic review. Pediatrics. 2013;132(1):140-52.

241. Prevost CP, Gleberzon B, Carleo B, Anderson K, Cark M, Pohlman KA. Manual therapy for the pediatric population: a systematic review. BMC Complement Altern Med. 2019;19(1):60.

242. Ozkan F, Zincir H. The effect of reflexology upon spasticity and function among children with cerebral palsy who received physiotherapy: three group randomised trial. Appl Nurs Res: ANR. 2017;36:128-34.

243. Elbasan B, Akaya KU, Akyuz M, Oskay D. Effects of neuromuscular electrical stimulation and Kinesio taping applications in children with cerebral palsy on postural control and sitting balance. $\mathrm{J}$ Back Musculoskelet Rehabil. 2018;31(1):49-55.

244. Sun-Young H, Sung YH. Effects of Vojta approach on diaphragm movement in children with spastic cerebral palsy. J Exerc Rehabil. 2018;14(6):1005-9.

245. Franki I, Desloovere K, De Cat J, Feys H, Molenaers G, Calders P, et al. The evidence-base for basic physical therapy techniques targeting lower limb function in children with cerebral palsy: a systematic review using the International Classification of Functioning, Disability and Health as a conceptual framework. J Rehabil Med(Stiftelsen Rehabiliteringsinformation). 2012;44(5): 385-95.

246. Myrhaug HT, Ostensjo S, Larun L, Odgaard-Jensen J, Jahnsen R. Intensive training of motor function and functional skills among young children with cerebral palsy: a systematic review and metaanalysis. BMC Pediatr. 2014;14:292.

247. Veneri D, Gannotti M, Bertucco M, Fournier Hillman SE. Using the International Classification of Functioning, Disability, and Health model to gain perspective of the benefits of yoga in stroke, multiple sclerosis, and children to inform practice for children with cerebral palsy: a meta-analysis. J Altern Complement Med. 2018;24(5):439-57.

248. Mak C, Whittingham K, Cunnington R, Boyd RN. Effect of mindfulness yoga programme MiYoga on attention, behaviour, and physical outcomes in cerebral palsy: a randomized controlled trial. Dev Med Child Neurol. 2018;60(9):922-32.

249. Liberati A, Altman DG, Tetzlaff J, Mulrow C, Gotzsche PC, Ioannidis JP, et al. The PRISMA statement for reporting systematic reviews and meta-analyses of studies that evaluate health care interventions: explanation and elaboration. J Clin Epidemiol. 2009;62(10):e1-34.

250. Palisano R, Rosenbaum P, Walter S, Russell D, Wood E, Galuppi B. Development and reliability of a system to classify gross motor 
function in children with cerebral palsy. Dev Med Child Neurol. 1997;39(4):214-23.

251. Eliasson A-C, Krumlinde-Sundholm L, Rsblad B, Beckung E, Arner M, Hrvall A-M, et al. The Manual Ability Classification System (MACS) for children with cerebral palsy: scale development and evidence of validity and reliability. Dev Med Child Neurol. 2006;48(7):549-54.

252. Khandaker G, Muhit M, Karim T, Smithers-Sheedy H, Novak I, Jones C, et al. Epidemiology of cerebral palsy in Bangladesh: a population-based surveillance study. Dev Med Child Neurol. 2019;61(5):601-9.

253. Fahey MC, Maclennan AH, Kretzschmar D, Gecz J, Kruer MC. The genetic basis of cerebral palsy. Dev Med Child Neurol. 2017;59(5):462-9.

254. Scher MS. Fetal neurology: principles and practice with a lifecourse perspective. Handb Clin Neurol. 2019;162:1-29.

255. Rosenbaum P, Paneth N, Leviton A, Goldstein M, Bax M, Damiano D, et al. A report: the definition and classification of cerebral palsy April 2006. Dev Med Child Neurol Suppl. 2007;109:8-14.

256. Kleim JA, Jones TA. Principles of experience-dependent neural plasticity: implications for rehabilitation after brain damage. J Speech, Language, Hearing Res: JSLHR. 2008;51(1):S225-39.

257. Mathewson MA, Lieber RL. Pathophysiology of muscle contractures in cerebral palsy. Phys Med Rehabil Clin N Am. 2015;26(1): $57-67$.

258. Von Walden F, Gantelius S, Liu C, Borgstrom H, Bjork L, Gremark $\mathrm{O}$, et al. Muscle contractures in patients with cerebral palsy and acquired brain injury are associated with extracellular matrix expansion, pro-inflammatory gene expression, and reduced rRNA synthesis. Muscle Nerve. 2018;58(2):277-85.

259. Booth CM, Cortina-Borja MJ, Theologis TN. Collagen accumulation in muscles of children with cerebral palsy and correlation with severity of spasticity. Dev Med Child Neurol. 2001;43(5): 314-20.

260. Hagglund G, Alriksson-Schmidt A, Lauge-Pedersen H, RodbyBousquet E, Wagner P, Westbom L. Prevention of dislocation of the hip in children with cerebral palsy: 20 -year results of a population-based prevention programme. The Bone \& Joint Journal. 2014;96-b(11):1546-52.
261. Shepherd RB, editor. Cerebral palsy in infancy. Oxford, England: Elsevier Health Sciences; 2014

262. Novak I, Hines M, Goldsmith S, Barclay R. Clinical prognostic messages from a systematic review on cerebral palsy. Pediatrics. 2012;130(5):e1285-312.

263. Verschuren O, Darrah J, Novak I, Ketelaar M, Wiart L. Healthenhancing physical activity in children with cerebral palsy: more of the same is not enough. Phys Ther. 2014;94(2):297-305.

264. Palisano RJ, Chiarello LA, King GA, Novak I, Stoner T, Fiss A. Participation-based therapy for children with physical disabilities. Disabil Rehabil. 2012;34(12):1041-52.

265. Benfer KA, Weir KA, Bell KL, Ware RS, Davies PS, Boyd RN. The Eating and Drinking Ability Classification System in a population-based sample of preschool children with cerebral palsy. Dev Med Child Neurol. 2017;59(6):647-54.

266. Blair E, Langdon K, McIntyre S, Lawrence D, Watson L. Survival and mortality in cerebral palsy: observations to the sixth decade from a data linkage study of a total population register and National Death Index. BMC Neurol. 2019;19(1):111.

267. Novak I, Morgan C, Adde L, Blackman J, Boyd RN, BrunstromHernandez J, et al. Early, accurate diagnosis and early intervention in cerebral palsy: advances in diagnosis and treatment. JAMA Pediatr. 2017;171(9):897-907.

268. Hubermann L, Boychuck Z, Shevell M, Majnemer A. Age at referral of children for initial diagnosis of cerebral palsy and rehabilitation: current practices. J Child Neurol. 2016;31(3):364-9.

269. Protzko J, Aronson J, Blair C. How to make a young child smarter: evidence from the database of raising intelligence. Perspect Psychol Sci: J Assoc Psychol Sci. 2013;8(1):25-40.

270. Polatajko HJ, Mandich A, McEwen SE. Cognitive orientation to daily occupational performance (CO-OP): a cognitive-based intervention for children and adults. Cognition, occupation, and participation across the life span: Neuroscience, neurorehabilitation, and models of intervention in occupational therapy, 3rd ed. Rockville, MD: American Occupational Therapy Association; US; 2011. p. 299-321.

Publisher's Note Springer Nature remains neutral with regard to jurisdictional claims in published maps and institutional affiliations. 